DOE 2008

Occupational

Radiation

Exposure

October 2009

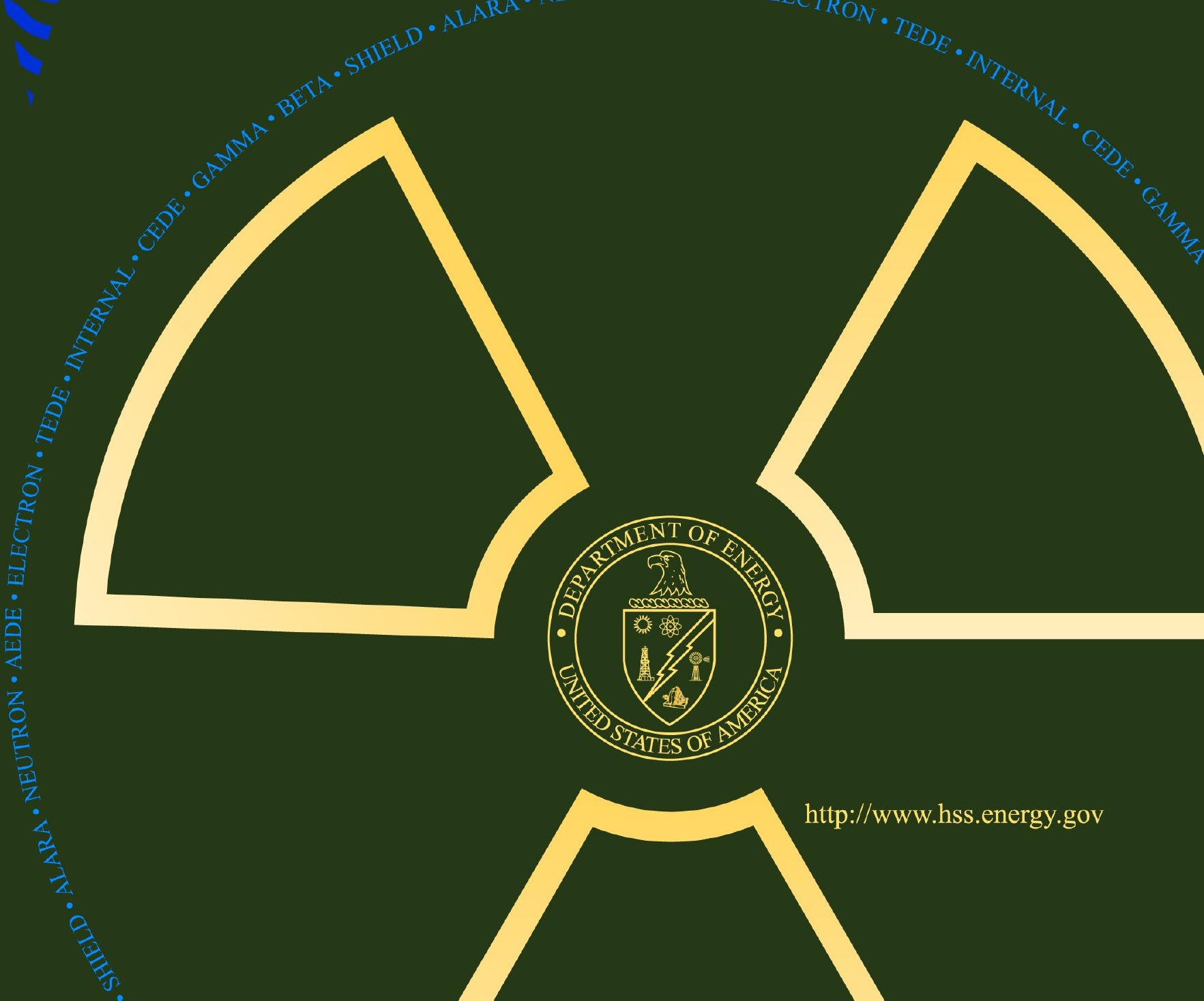


This document is available on the Department of Energy REMS Program Web Site at: http://www.hss.energy.gov 
A major priority of the U.S. Department of Energy (DOE) is to ensure the health, safety, and security of DOE employees, contractors, and subcontractors. The Office of Health, Safety and Security (HSS) provides the corporate-level leadership and strategic vision necessary to better coordinate and integrate health, safety, environment, security, enforcement, and independent oversight programs. One function that supports this mission is the DOE Corporate Operating Experience Program that provides collection, analysis, and dissemination of performance indicators, such as occupational radiation exposure information. This analysis supports corporate decision-making and synthesizes operational information to support continuous environment, safety, and health improvement across the DOE complex.

A key safety focus for DOE is to maintain radiation exposures of its workers below administrative control levels (ACL) and DOE limits and to further reduce these exposures to levels that are "as low as reasonably achievable (ALARA)."The annual DOE 2008 Occupational Radiation Exposure Report provides an evaluation of DOE-wide performance regarding compliance with DOE Part 835 dose limits and ALARA process requirements and an overview of the status of radiation exposures of the DOE workforce. In addition, this report provides data to DOE organizations responsible for developing policies for protection of individuals from the effects of radiation. This report is primarily a tool for managing radiological safety programs and provides useful information to epidemiologists, researchers, and national and international agencies involved in developing policies to protect individuals from harmful effects of radiation. The overall radiation dose decreased from 2007 to 2008 in terms of collective dose, although there were more individuals who received a measurable dose. The average measurable dose is calculated by dividing the collective dose by the number of individuals with a measurable dose. Since the collective total effective dose equivalent (TEDE) decreased by 108 person-rems and the number of individuals with a measurable dose increased slightly, the resultant average measurable dose decreased. In 2008, one individual received a dose to the bone surface in excess of the 50 rems (500 millisievert [mSv]) DOE annual organ dose limit.

One of the objectives of this report is to provide timely, useful, accurate, and complete information to the target audience. As part of a continuing improvement process, we would appreciate your response to the user survey included at the end of this report.

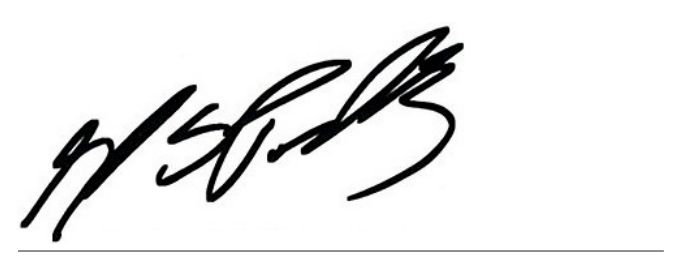

Glenn S. Podonsky

Chief Health, Safety and Security Officer

Office of Health, Safety and Security 
This page intentionally left blank. 
FOREWORD iii

EXECUTIVE SUMMARY ix

\section{SECTION 1-INTRODUCTION}

1.1 Report Organization

1.2 Report Availability

\section{SECTION 2-STANDARDS AND REQUIREMENTS}

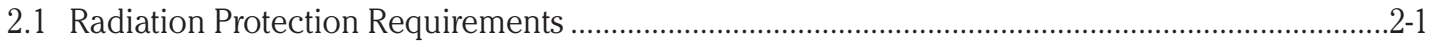

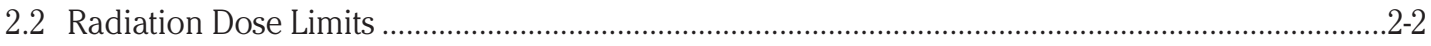

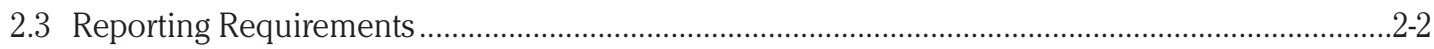

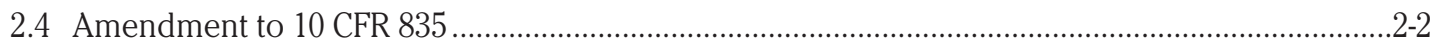

\section{SECTION 3-OCCUPATIONAL RADIATION DOSE AT DOE}

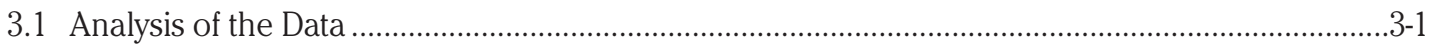

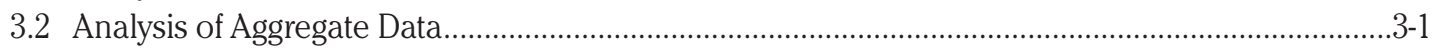

3.2.1 Number of Records for Monitored Individuals .......................................................................

3.2.2 Number of Records for Individuals with Measurable Dose...................................................

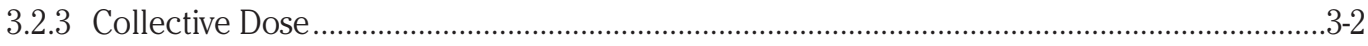

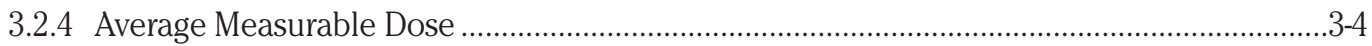

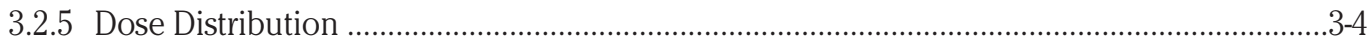

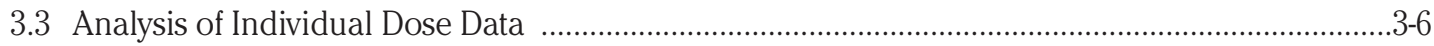

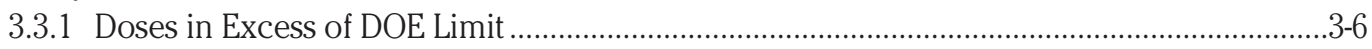

3.3.2 Doses in Excess of Administrative Control Level ...................................................................... $3-6$

3.3.3 Internal Depositions of Radioactive Material .............................................................................

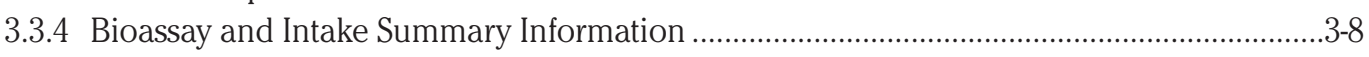

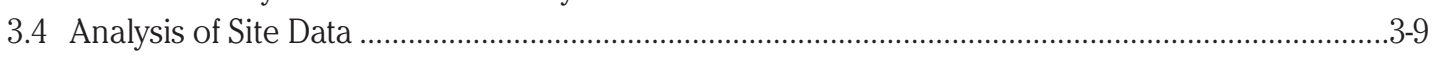

3.4.1 Collective TEDE by Site and Other Facilities …………........................................................ $3-9$

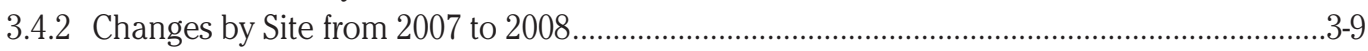

3.4.3 Activities Significantly Contributing to Collective Dose in 2008 .........................................3-12

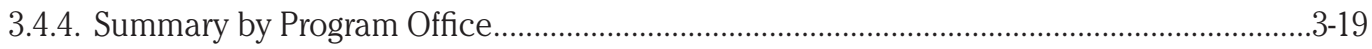

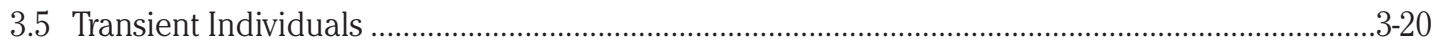

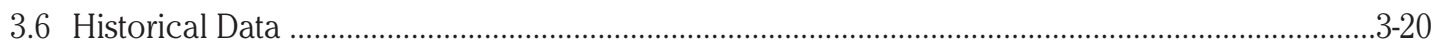

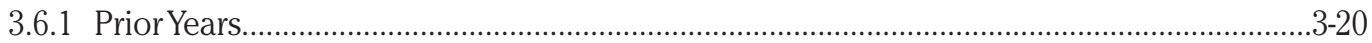

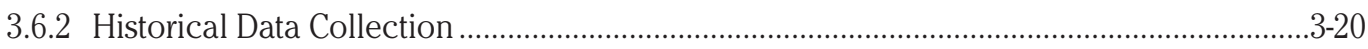

3.7 Comparison of DOE Dose to Other Activities .................................................................................. $3-22$

3.7.1 Comparison with Activities Regulated by the Nuclear Regulatory Commission ..................3-22

\section{SECTION 4-ALARA ACTIVITIES AT DOE}

4.1 Submitting ALARA Project Descriptions for Future Annual Reports.......................................................... $4-1$

4.2 Operating Experience Program....................................................................................................... $4-1$

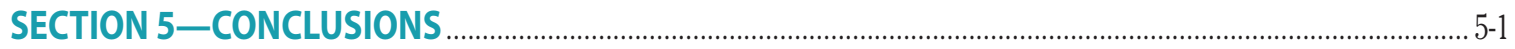

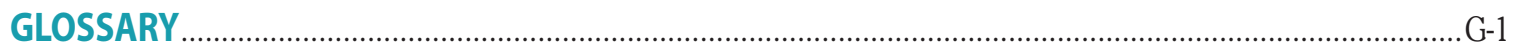

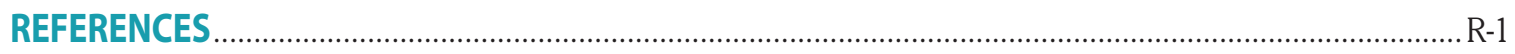

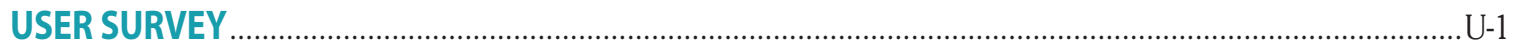




\section{LIST OF EXHIBITS}

Exhibit ES-1: Collective TEDE (person-rem), 2004-2008 ................................................................................................................ix

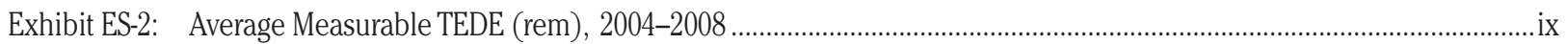

Exhibit 2-1: C Current Laws and Requirements Pertaining to This Report ...................................................................................2-1

Exhibit 2-2: DOE Dose Limits from 10 CFR 835

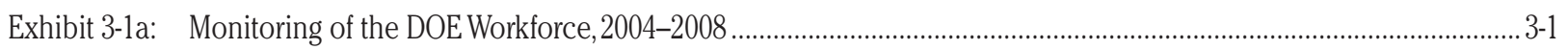

Exhibit 3-1b: Monitoring of the DOE Workforce, 2004-2008 .......................................................................................................... $3-2$

Exhibit 3-2: Components of TEDE, 2004-2008

Exhibit 3-3: $\quad$ Average Measurable TEDE, 2004-2008 ……………............................................................................... $3-4$

Exhibit 3-4: $\quad$ Distribution of TEDE by Dose Range, 2004-2008................................................................................................. 3-5

Exhibit 3-5: Percentage of Collective TEDE Above Dose Values During 2004-2008 ........................................................................3-5

Exhibit 3-6: $\quad$ Number of Individuals Exceeding 5 rems (TEDE), 2004-2008 ………………..................................................... $3-6$

Exhibit 3-7: $\quad$ Number of Doses in Excess of the DOE 2 rems ACL, 2004-2008 ………………................................................. 3-6

Exhibit 3-8: $\quad$ Doses in Excess of DOE Limit, 2004-2008 .....................................................................................................

Exhibit 3-9: $\quad$ Number of Internal Depositions, Collective CEDE, and Average Measurable CEDE, 2004-2008 ............................... 3-7

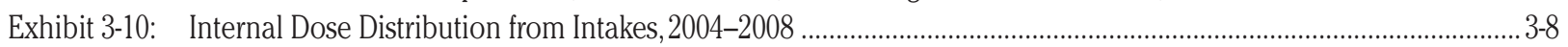

Exhibit 3-11: Bioassay Measurements, 2006-2008 ………………………………………………………………………...... 3-8

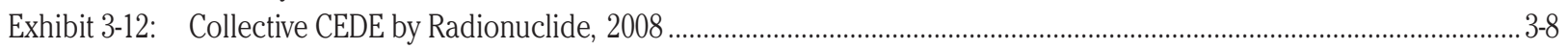

Exhibit 3-13: Collective TEDE by DOE Site for 2006-2008 …………………………………...................................................... $3-9$

Exhibit 3-14: Collective TEDE and Number of Individuals with Measurable TEDE by DOE Site, 2006-2008 …..........................3-10

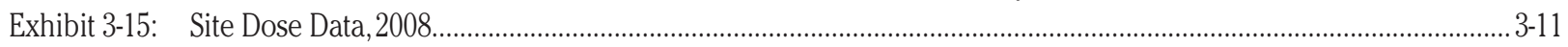

Exhibit 3-16: Activities Significantly Contributing to Collective TEDE in 2008 …….............................................................. 3-12

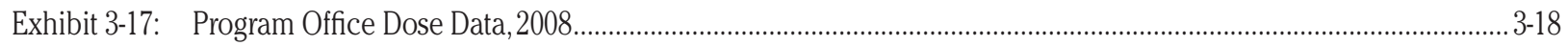

Exhibit 3-18: $\quad$ Dose Distribution of Transient Workers, 2004-2008 .................................................................................................. 3-19

Exhibit 3-19: Collective Dose and Average Measurable Dose, 1974-2008 .................................................................................... 3-21

Exhibit 3-20: Number of Workers with Measurable Dose and Average Measurable Dose, 1974-2008 _....................................... 3-21

Exhibit 3-21: Comparison of Occupational Exposure for DOE and NRC, 2004-2008 .................................................................. 3-22

Exhibit 5-1: 2008 Radiation Exposure Summary …………………............................................................................................. 5-1 
ACL

AEDE

AEC

ALARA

CDE

CEDE

D\&D

DDE

DOE

EM

EPA

ETTP

HSS

INTEC

LANL

LDE

LLNL

$\mathrm{mSv}$

NE

NNSA

ORISE

ORNL

PFP

REMS

$\mathrm{SC}$

SDE-ME

SDE-WB

SRS

Sv

TEDE

TODE

TVA

UNSCEAR

WIPP

Y-12
Administrative Control Level

Annual Effective Dose Equivalent

Atomic Energy Commission

As Low As Reasonably Achievable

Committed Dose Equivalent

Committed Effective Dose Equivalent

Decontamination and Decommissioning

Deep Dose Equivalent

U.S. Department of Energy

Office of Environmental Management

U.S. Environmental Protection Agency

East Tennessee Technology Park

Office of Health, Safety and Security

Idaho Nuclear Technology and Engineering Center

Los Alamos National Laboratory

Lens (of the Eye) Dose Equivalent

Lawrence Livermore National Laboratory

Millisievert

Office of Nuclear Energy, Science and Technology

National Nuclear Security Administration

Oak Ridge Institute for Science and Education

Oak Ridge National Laboratory

Plutonium Finishing Plant

Radiation Exposure Monitoring System

Office of Science

Shallow Dose Equivalent to the Maximally Exposed Extremity

Shallow Dose Equivalent to the Skin of the Whole Body

Savannah River Site

Sieverts

Total Effective Dose Equivalent

Total Organ Dose Equivalent

Tennessee Valley Authority

United Nations Scientific Committee on the Effects of Atomic Radiation

Waste Isolation Pilot Plant

Y-12 National Security Complex 
This page intentionally left blank. 


\section{Executivesummary 10 y}

The U.S. Department of Energy (DOE) Office of Corporate Safety Analysis (HS-30) within the Office of Health, Safety and Security (HSS) publishes the annual DOE Occupational Radiation Exposure Report to provide an overview of the status of radiation protection practices at DOE* The DOE 2008 Occupational Radiation Exposure Report provides an evaluation of DOE-wide performance regarding compliance with DOE Part 835 dose limits and as low as reasonably achievable (ALARA) process requirements. In addition, the report provides data to DOE organizations responsible for developing policies for protection of individuals from the effects of radiation. This report provides a summary and an analysis of occupational radiation exposure information from the monitoring of individuals involved in DOE activities. The occupational radiation exposure information is analyzed in terms of aggregate data, dose to individuals, and dose by site over the past 5 years.

One of the report's features includes the collective total effective dose equivalent (TEDE)-an indicator of the overall amount of radiation dose received during the conduct of operations at DOE. Over the past 10year period, $99.99 \%$ of the individuals receiving measurable dose have received doses below the 2 rems (20 mSv) TEDE administrative control level (ACL), which is well below the DOE regulatory limit of 5 rems (50 mSv) TEDE. The DOE collective TEDE decreased by 13\% from 2007 to 2008, as shown in Exhibit ES-1. This is the fifth consecutive year that the collective TEDE has decreased. The decrease in 2008 was due primarily to the removal of radioactive materials, decreases in the amount of work performed that directly involves radioactive materials, and a safety-driven pause in operations at Los Alamos National Laboratory (LANL).

It should be noted that while 10 CFR 835 was revised as of June 2007, full implementation is not required until July of 2010. Some sites are still in the process of transition and therefore this report continues to use the previous dose terminology of 10 CFR 835, such as TEDE.

Sites that contributed to the decrease in the number of workers with measurable dose include Fermilab, Lawrence Livermore National Laboratory (LLNL), LANL, Sandia, the Office of River Protection, and Pantex, while increases occurred at Hanford, Oak Ridge National Laboratory (ORNL), Savannah River Site (SRS), Idaho, and Y-12 National Security Complex (Y-12 NSC). Overall from 2007 to 2008, there was an increase in the number of workers with measurable dose.

Exhibit ES-1:

Collective TEDE (person-rem), 2004-2008.

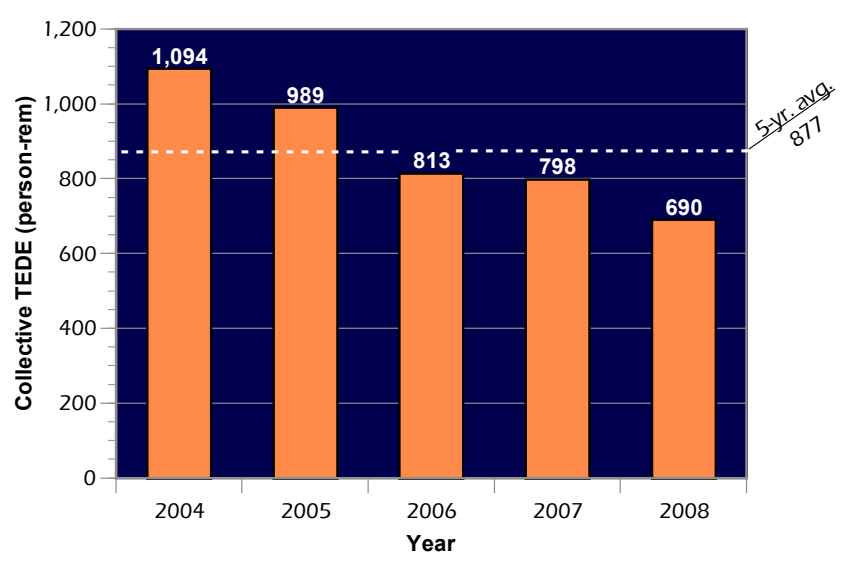

Exhibit ES-2:

Average Measurable TEDE (rem), 2004-2008.

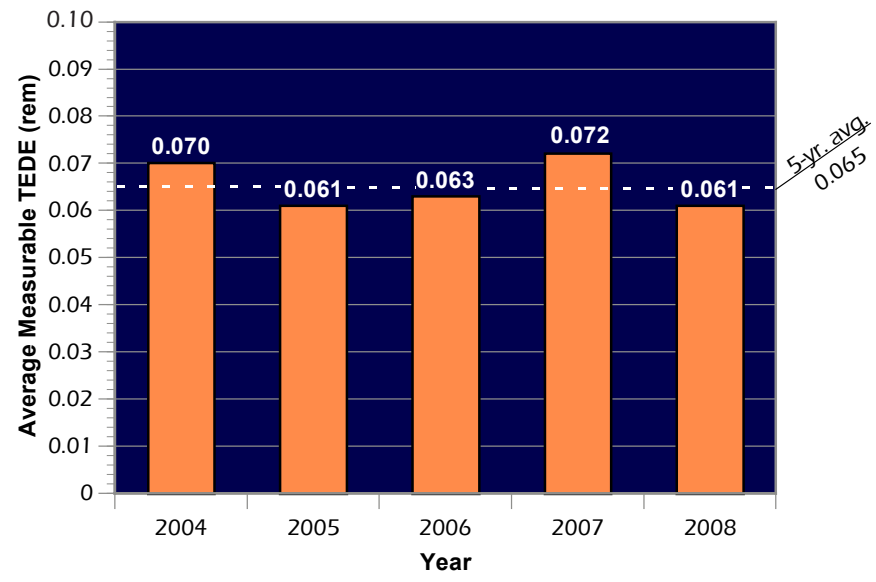

* DOE is defined to include the National Nuclear Security Administration (NNSA) sites. 
The TEDE is comprised of the external deep dose equivalent (DDE), which includes neutron and photon radiation, and the internal committed effective dose equivalent (CEDE), which results from the intake of radioactive material into the body.The photon, neutron and internal dose components of the collective TEDE decreased by $16 \%, 5 \%$ and $11 \%$ from 2007 to 2008 , respectively.

Another primary indicator of the level of radiation exposure covered in this report is the average measurable dose, which normalizes the collective dose over the population of workers who actually received a measurable dose. The average measurable TEDE decreased by 15\% from 2007 to 2008, as shown in Exhibit ES-2. The collective dose and the average measurable dose both decreased, while the number of individuals who received a measurable dose increased.

Additional analyses show that the dose distribution in 2008 was similar to the distribution in 2007 with the exception of the one individual that exceeded the 2 rems (20 millisievert [mSv]) DOE administrative control level (ACL) limit. Most of the reduction in monitored individuals occurred in the number of individuals with no measurable dose and the number of individuals receiving less than $0.1 \mathrm{rem}(1 \mathrm{mSv})$. The number of individuals receiving doses between $0.1 \mathrm{rem}(1 \mathrm{mSv})$ and 2 rems (20 mSv) in 2008 decreased by nearly $9 \%$ of the number in 2007.

In conclusion, the assessment of occupational radiation exposure for 2008 continues to show a decreasing trend in collective dose and the number of individuals with a measurable dose, while the average measurable dose decreased significantly. Primary factors in the decrease in collective dose for 2008 were a reduction in activities involving radiation at several DOE sites. The decrease in the average measurable dose was due to an increase in the number of individuals with measurable dose (particularly measurable doses below $0.1 \mathrm{rem}$ ). The one individual who received a dose above 2 rems ( $20 \mathrm{mSv}$ ) exceeding the ACL, also received 60 rems committed dose equivalent (CDE) to the bone surface exceeding the 50 rems DOE annual limit to an organ or tissue. With the exception of one incident, in 2008, all DOE operations complied with DOE Part 835 dose limits and the DOEwide dose constraints. Only a small fraction of the DOE workforce received measurable doses and the average measurable dose was $1 \%$ of the DOE limit.

As DOE continues consolidation and remediation efforts, it is anticipated that the decreasing trend in collective dose and the number of individuals with measurable dose will continue over the next several years. At some sites where remediation activities are increased or accelerated, a temporary increase in dose may be observed at the site, but should decrease once the effects of the remediation result in lower dose rates and fewer opportunities for exposure.The average measurable dose may fluctuate as fewer individuals receive dose, but should remain low as radiation protection practices and ALARA principles continue to reduce dose to individuals.

To access this report and other information on occupational radiation exposure at DOE, visit the DOE HSS web site at

http://www.hss.energy.gov

Select HSS Reporting Databases from the HSS Quick Reference and then select the Radiation Exposure Monitoring System (REMS). 
The DOE 2008 Occupational Radiation Exposure Report provides analyses of occupational radiation exposures incurred by individuals at the U.S. Department of Energy (DOE) facilities during 2008. This report includes occupational radiation exposure information for all DOE employees, contractors, and subcontractors, as well as members of the public who are monitored for exposure to radiation. The $92 \mathrm{DOE}$ organizations submitting radiation exposure reports for 2008 have been grouped into 30 sites across the complex. This information has been analyzed and trended over time to provide a measure of DOE's performance in protecting its workers from radiation.

\subsection{Report Organization}

This report is organized into the five sections listed below. In an effort to further streamline the printed report, most of the supporting technical information, tables of data, and additional items that were previously provided in the report and the appendices will be available on the DOE web site for Information on Occupational Radiation Exposure. A User Survey form is included at the end of this report and users are encouraged to provide feedback to improve this report.

\subsection{Report Availability}

Requests for additional copies of this report, requests for access to the data files or individual dose records used to compile this report, and suggestions and comments should be directed to

\section{Ms. Nirmala Rao, HS-30}

DOE REMS Project Manager

U.S. Department of Energy

1000 Independence Avenue, SW

Washington, D.C. 20585-0270

E-mail:nimi.rao@hq.doe.gov

Visit the DOE web site at http://www.hss.energy.gov for more information on occupational radiation exposure, such as the following:

- Annual occupational radiation exposure reports in pdf files since 1974

- Guidance on reporting radiation exposure information to the DOE Headquarters Radiation Exposure Monitoring System (REMS)

$\checkmark$ Guidance on how to request a dose history for an individual

- Statistical data since 1987 for analysis

- Applicable DOE orders and manuals for the record keeping and reporting of occupational radiation exposure at DOE

- "As low as reasonably achievable" (ALARA) activities at DOE

\footnotetext{
Section One

Section Two

Section Three

Section Four

Section Five

Appendices

Provides a description of the content and organization of this report.

Provides a discussion of the radiation protection and dose reporting requirements.

Presents the occupational radiation dose data from monitored individuals at DOE facilities for 2008. The data are analyzed to show trends over the past five years.

Includes instructions to submit successful ALARA projects within the DOE complex.

Presents conclusions based on the analysis contained in this report.

In an effort to streamline this publication, the appendices are now offered in color on the DOE Radiation Exposure Web site. Please visit http://www.hss.energy.gov and select HSS Reports and Occupational Radiation Exposure Reports to review.
} 
This page intentionally left blank. 


\section{Standards and Requirements}

One of DOE's primary objectives is to provide a safe and healthy workplace for all employees and contractors. To meet this objective, DOE's Office of Health, Safety and Security (HSS) establishes comprehensive and integrated programs for the protection of workers from hazards in the workplace, including ionizing radiation. The basic DOE standards for occupational radiation protection are radiation dose limits, which establish maximum permissible doses to workers. In addition to the requirement that radiation doses not exceed the limits, contractors and subcontractors are required to maintain exposures ALARA.

This section discusses the radiation protection standards and requirements in effect for 2008. For more information on past requirements, visit the DOE web site for DOE Directives, Regulations, and Standards at

http://www.hss.energy.gov.

\subsection{Radiation Protection Requirements}

DOE radiation protection standards in effect in 2008 were based on Federal guidance for protection against occupational radiation exposure promulgated by the U.S. Environmental Protection Agency (EPA) in 1987.[1] This guidance, initially implemented by DOE in 1989, is based on the 1977 recommendations of the International Commission on Radiological Protection (ICRP) [2] and the 1987 recommendations of the National Council on Radiation Protection and Measurements (NCRP). [3] This guidance recommends that internal organ dose be added to the external wholebody dose to determine the total effective dose equivalent (TEDE). Prior to this guidance, the whole-body dose and internal organ dose were each limited separately.

In summary, the current laws and requirements for occupational radiation protection pertaining to the information collected and presented in this report are shown in Exhibit 2-1.

Exhibit 2-1:

Current Laws and Requirements Pertaining to This Report.

\begin{tabular}{|l|l|l|}
\hline \multicolumn{1}{|c|}{ Title } & \multicolumn{1}{c}{ Date } & \multicolumn{1}{c}{ Description } \\
\hline $\begin{array}{l}\text { 10 CFR 835, “Occupational } \\
\text { Radiation Protection." [4] }\end{array}$ & $\begin{array}{l}\text { Issued 12/14/93. } \\
\text { Amended 11/4/98. } \\
\text { Amended 6/8/07. }\end{array}$ & $\begin{array}{l}\text { Establishes radiation protection standards, limits, and } \\
\text { program requirements for protecting individuals from } \\
\text { ionizing radiation that results from the conduct of DOE } \\
\text { activities. }\end{array}$ \\
\hline DOE Order 231.1A [5] & Approved 8/19/03. & $\begin{array}{l}\text { Requires the annual reporting of occupational radiation } \\
\text { exposure records to the DOE REMS repository. }\end{array}$ \\
\hline DOE Manual 231.1-1A [6] & Approved 3/19/04. & $\begin{array}{l}\text { Specifies the format and content of the reports required by } \\
\text { DOE Order 231.1A. Readers should note that the revisions } \\
\text { of this manual affect the content and reporting of radiation } \\
\text { exposure records that were reported to the DOE REMS } \\
\text { repository beginning with the 2005 monitoring year. }\end{array}$ \\
\hline
\end{tabular}




\subsection{Radiation Dose Limits}

Radiation dose limits are codified in 10 CFR 835.202, 206,207, and 208 [4] and are summarized in Exhibit 2-2.

\subsection{Reporting Requirements}

On August 19,2003, DOE approved and issued the revised DOE Order 231.1A. [5] The DOE Manual 231.1-1A, [6] which details the format and content of reporting radiation exposure records to DOE, was approved on March 19,2004.The revisions affected the content and reporting of radiation exposure records, beginning with the 2005 monitoring year.

\subsection{Amendment to 10 CFR 835}

In August 2006, DOE published a proposed amendment to 10 CFR 835 in the Federal Register, and in June 2007, the final rule was published. The amendment

Specified new dosimetric terminology and quantities based on ICRP 60/68 in place of ICRP 26/30

- Specified ICRP 60 tissue weighting factors in place of ICRP 26 weighting factors

- Specified ICRP 60 radiation weighting factors in place of ICRP 26 quality factors

- Amended other parts of the regulation that changed as a result of adopting ICRP 60 dosimetry system

Used the ICRP 68 dose conversion factors to determine values for the derived air concentrations (DACs)

Other changes intended to enhance radiation protection

Exhibit 2-2:

DOE Dose Limits from 10 CFR 835.

\begin{tabular}{|c|c|c|c|c|}
\hline $\begin{array}{l}\text { Personnel } \\
\text { Category }\end{array}$ & $\begin{array}{l}\text { Section of } \\
10 \text { CFR } 835\end{array}$ & Type of Exposure & Acronym & $\begin{array}{l}\text { Annual } \\
\text { Limit }\end{array}$ \\
\hline $\begin{array}{l}\text { General } \\
\text { employees }\end{array}$ & 835.202 & $\begin{array}{l}\text { Total effective dose equivalent. } \\
\text { Deep dose equivalent + committed } \\
\text { dose equivalent to any organ or } \\
\text { tissue (except lens of the eye). } \\
\text { This is often referred to as } \\
\text { the total organ dose equivalent. } \\
\text { Lens (of the eye) dose equivalent. } \\
\text { Shallow dose equivalent to the skin } \\
\text { of the whole body or to any } \\
\text { extremity. }\end{array}$ & $\begin{array}{l}\text { TEDE } \\
\text { DDE+CDE } \\
\text { (TODE) } \\
\text { LDE } \\
\text { SDE-WB } \\
\text { and } \\
\text { SDE-ME }\end{array}$ & 15 rems \\
\hline $\begin{array}{l}\text { Declared } \\
\text { pregnant } \\
\text { workers * }\end{array}$ & 835.206 & Total effective dose equivalent. & TEDE & $\begin{array}{l}0.5 \text { rem per } \\
\text { gestation } \\
\text { period }\end{array}$ \\
\hline Minors & 835.207 & Total effective dose equivalent. & TEDE & 0.1 rem \\
\hline $\begin{array}{l}\text { Members of } \\
\text { the public in a } \\
\text { controlled area }\end{array}$ & 835.208 & Total effective dose equivalent. & TEDE & 0.1 rem \\
\hline
\end{tabular}

* Limit applies to the embryo/fetus. 
The rule became effective on July 9,2007, and is required to be fully implemented by the DOE sites by July 9 , 2010.Therefore, the revisions were not applicable to all sites during this reporting period, although some began complying with the new requirements during 2008.

Several aspects of the amendment impact the record keeping and reporting of DOE occupational radiation exposure. A revision of the DOE Manual 231.1-1A will be issued in order to conform to the amended rule. The following is a summary of the changes that will affect the manual and the reporting of radiation exposure records:

$\checkmark$ A change in dosimetric terms

- A change in weighting factors to tissue weighting factors and a redefinition of the tissue weighting factor remainder

- A change in quality factors to radiation weighting factors; most significantly this affects neutron dose assessment

$\checkmark$ A change eliminating the requirement for recording of internal dose for any monitoring result estimated to correspond to an individual receiving less than 0.01 rem ( 0.1 millisievert $[\mathrm{mSv}])$ committed effective dose

$\checkmark$ Addition of specific organ dose reporting for the colon, liver, stomach, esophagus, bladder, and skin
In anticipation of the revision to Manual 231.1-1A, an optional format for reporting under the amendment to 835 has been developed and is available on the REMS web site. The optional format is an acceptable method of reporting radiation exposure records until the manual is officially revised.

When issued, the revised draft Manual 231.1-1A will be available for review and comment through the DOE RevCom process at http://directives.doe.gov. 
This page intentionally left blank. 


\section{Occupational Radiation Dose at DOE}

\subsection{Analysis of the Data}

Certain key indicators have been determined to be useful in evaluating the occupational radiation exposures received at DOE facilities. The key indicators are analyzed to identify and correlate parameters having an impact on radiation dose at DOE.

Key indicators for the analysis of aggregate data are

- number of records for monitored individuals

individuals with measurable dose

$\checkmark$ collective dose

$\checkmark$ average measurable dose

$\checkmark$ dose distribution

Analysis of individual dose data includes an examination of

- doses exceeding the 5 rems ( $50 \mathrm{mSv}$ ) DOE regulatory limit

$\checkmark$ doses exceeding the 2 rems (20 mSv) DOE administrative control level (ACL)

Additional information is provided in this report concerning activities at sites contributing to the majority of the collective dose.

\subsection{Analysis of Aggregate Data}

\subsubsection{Number of Records for Monitored Individuals}

The number of records for monitored individuals represents the size of the DOE worker population monitored for radiation dose.The number represents the sum of all records for monitored individuals, including all DOE employees, contractors, and subcontractors, as well as members of the public. The number of monitored individuals is the number of monitoring records submitted by each site. Because individuals may have more than one monitoring record, they may be counted more than once. Although an individual may be counted more than once, the overall effect on the numbers and analysis is minimal. The number of records for monitored individuals is an indication of the size of a dosimetry program, but it is not necessarily an indication of the size of the exposed workforce. This is because of the conservative practice at some DOE facilities of providing radiation dose monitoring to individuals for reasons other than the potential for exposure to radiation and/or radioactive materials exceeding the monitoring thresholds. Many individuals are monitored for reasons such as security, administrative convenience, and legal liability. Some sites offer monitoring for any individual who requests monitoring, independent of the potential for exposure. For this reason, the number of records for workers who receive a measurable dose best represents the exposed workforce.

\subsubsection{Number of Records for Individuals with Measurable Dose}

DOE uses the number of individuals receiving a measurable dose to represent the exposed workforce size.The number of individuals with a measurable dose includes any individual with a reported detectable dose greater than zero TEDE.

\begin{tabular}{|l} 
Exhibit 3-1a: \\
Monitoring of the DOE Workforce, 2004-2008.
\end{tabular}

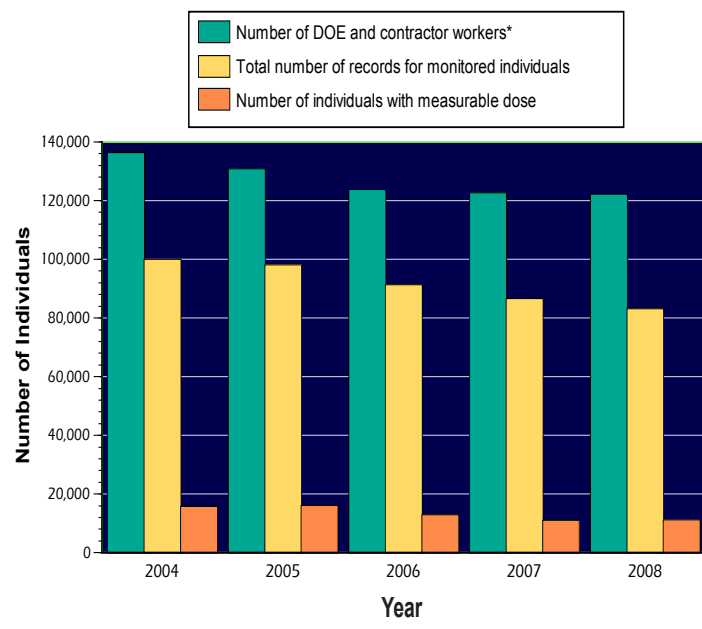

*The number of DOE and contractor workers was determined from the tota annual work hours at DOE [7] converted to full-time equivalents.

For $2008,68 \%$ of the DOE workforce was monitored for radiation dose, and $14 \%$ of monitored individuals received a measurable dose. 
Over the past 10-year period, $99.99 \%$ of the individuals receiving measurable dose have received doses below the 2 rems ( $20 \mathrm{mSv}$ ) TEDE administrative control level (ACL), which is well below the DOE regulatory limit of 5 rems $(50 \mathrm{mSv})$ TEDE.

Exhibits 3-1a and 3-1b show the number of DOE and contractor workers, the total number of workers monitored for radiation dose, the number of individuals with a measurable dose, and the relative percentages for the past 5 years.

Over the past 5 years, the percentage of individuals monitored for radiation exposure has remained within $4 \%$ of the 5 -year average; the percentage of monitored individuals receiving any measurable radiation dose each year has been within $2 \%$ of the 5-year average.

Twelve of the 30 reporting sites experienced decreases in the number of workers with a measurable dose from 2007 to 2008. The largest decrease in total number of workers with a measurable dose occurred at Los Alamos National Laboratory (LANL). The largest increase in the number of workers receiving a measurable dose occurred at the Hanford Site. A discussion of activities at the highest dose facilities is included in Section 3.4.3.

Exhibit 3-1b:

Monitoring of the DOE Workforce, 2004-2008.

\begin{tabular}{|c|c|c|c|c|c|}
\hline Year & $\begin{array}{l}\text { DOE \& } \\
\text { Contractor } \\
\text { Workforce }\end{array}$ & $\begin{array}{l}\text { Number of } \\
\text { Workers } \\
\text { Monitored }\end{array}$ & $\begin{array}{l}\text { Percent of } \\
\text { Workers } \\
\text { Monitored* }\end{array}$ & $\begin{array}{c}\text { Number } \\
\text { Monitored } \\
\text { w/Measurable } \\
\text { Dose }\end{array}$ & $\begin{array}{c}\text { Percent } \\
\text { Monitored } \\
\text { w/Measurable } \\
\text { Dose* }\end{array}$ \\
\hline 2004 & 136,353 & 100,011 & $73 \% \nabla$ & 15,739 & $16 \% \nabla$ \\
\hline 2005 & 130,795 & 98,040 & $75 \% \Delta$ & 16,136 & $16 \%$ \\
\hline 2006 & 123,768 & 91,280 & $74 \% \nabla$ & 12,953 & $14 \% \nabla$ \\
\hline 2007 & 122,660 & 86,651 & $71 \% \nabla$ & 11,102 & $13 \% \nabla$ \\
\hline 2008 & 122,139 & 83,208 & $68 \% \nabla$ & 11,287 & $14 \% \Delta$ \\
\hline 5-Year Average & 127,143 & 91,838 & $72 \%$ & 13,443 & $15 \%$ \\
\hline
\end{tabular}

*Up arrows indicate an increase from the previous year's value. Down arrows indicate a decrease from the previous year's value.

\subsubsection{Collective Dose}

The collective dose is the sum of the dose received by all individuals with a measurable dose and is measured in units of person-rem (person-sievert [Sv]). The collective dose is an indicator of the overall radiation exposure at DOE facilities and includes the dose to all DOE employees, contractors, and subcontractors, as well as members of the public who are monitored during a visit to a DOE facility. DOE monitors the collective dose as one measure of the overall performance of radiation protection programs to keep individual exposures and collective exposures ALARA.

As shown in Exhibit 3-2, the collective TEDE decreased at DOE by $13 \%$ from 798 person-rems ( 7.98 person-Sv) in 2007 to 690 person-rems (6.90 person-Sv) in 2008.

The internal dose is based on the 50-year committed effective dose equivalent (CEDE) methodology, which assigns the projected dose delivered to the individual over the next 50 years to the year when the intake occurred. The internal dose component decreased by $11 \%$ from 65.4 person-rems (654 person-mSv) in 2007 to 58.0 person-rems ( 580 person-mSv) in 2008. The collective photon dose decreased by $16 \%$ from 605 person-rems (6.05 person-Sv) in 2007 to 511 person-rems (5.11 person-Sv) in 2008.

The neutron component of the TEDE decreased by $5 \%$ from 127 person-rems (1.27 person-Sv) in 2007 to 121 personrems (1.21 person-Sv) in 2008. This is due primarily to the $26 \%$ decrease in neutron dose at Hanford. Hanford and SRS process plutonium, which can result in a neutron dose from the alpha/neutron reaction with beryllium and from spontaneous fission of the plutonium. 

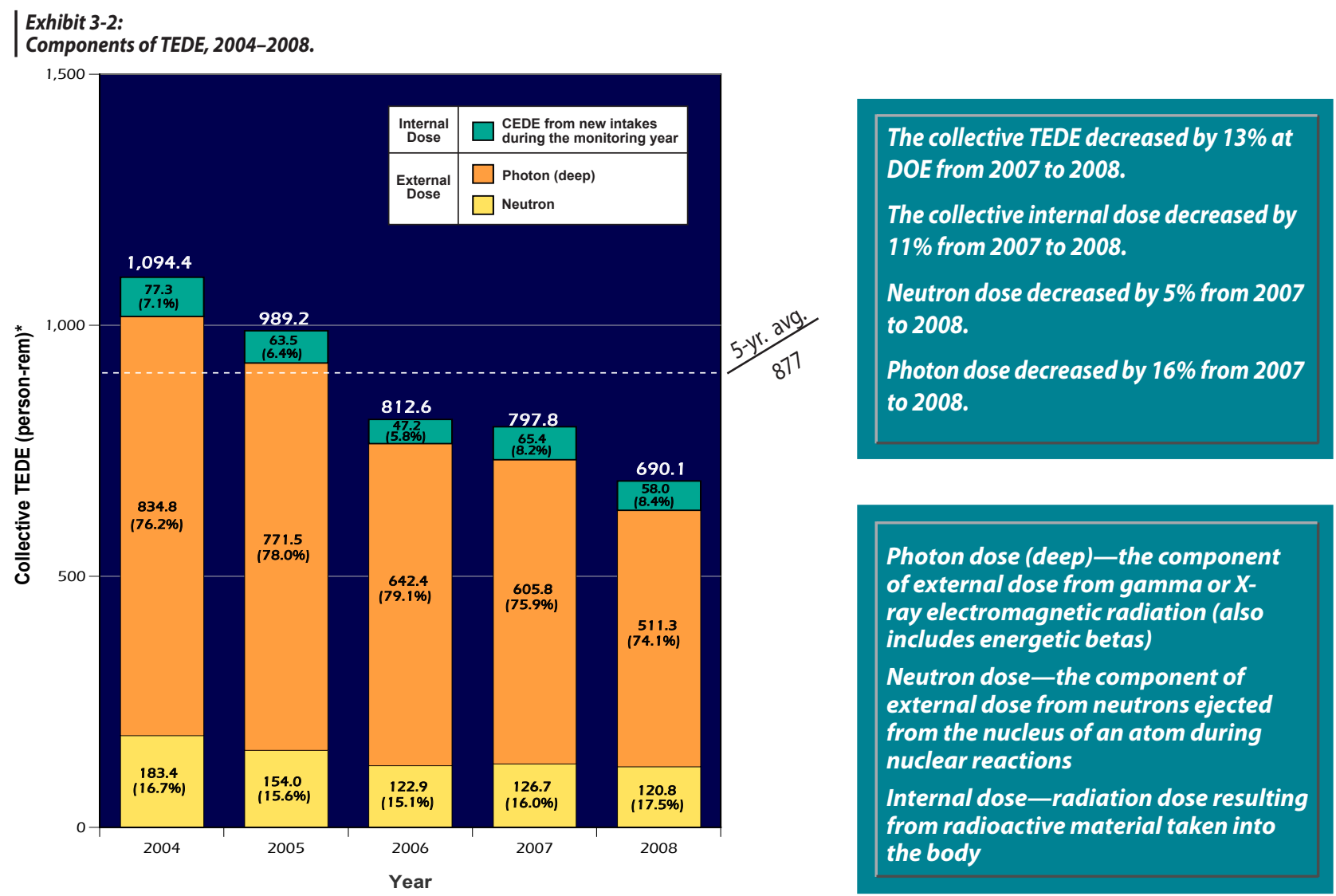

* The percentages in parentheses represent the percentage of each dose component to the collective TEDE.

Sixty percent of the DOE sites (18 of 30 sites) reported decreases in the collective TEDE from the 2007 values. The five sites that contributed to the majority of the DOE collective TEDE in 2008 were (in descending order of collective dose for 2008) Savannah River (18\%), Idaho (17\%), Oak Ridge (17\%), Los Alamos (16\%), and Hanford (15\%). Two of these five sites reported increases in the collective TEDE, while three sites reported decreases.

The two sites that reported increases in the collective dose attributed the increases to the following:

- Expanded activities at Savannah River that included more time than anticipated for the Central Laboratory High Activity Drain replacement and response to elevated dose rates at the Saltstone Vault 4 passive vents, an increase in the number of Savannah River National Laboratory (SRNL) High Activity Gallery entries, Hanford receipts in K-area Interim Surveillance (KIS), and drum re-packaging of transuranic wastes in multiple facilities.
At Oak Ridge National Laboratory (ORNL), increased activities at the High Flux Isotope Reactor,Spallation Neutron Source, and Holifield Radioactive Ion Beam Facilities that operated during most of the year in addition to maintenance and research activities associated with these facilities.

The three sites that reported decreases in the collective dose attributed the decreases to the following:

KE basin sludge removal and removal of high-dose items from the basins were completed and the basin was dewatered and filled with a controlled density fill, substantially reducing dose rates during the remaining decontamination and decommissioning (D\&D) activities at Hanford. Additionally, doses from the Waste Stabilization and Disposal Project decreased due to reduction in work activities.

$\checkmark$ The primary contributor at Los Alamos was the criticality safety-driven pause in operations 
begun in the fourth quarter of 2007, which caused a significant reduction in work throughout the facility. After formal reviews, most operations resumed by July 2008 with the remaining operations fully resumed by September 2008.

The overall decrease at Idaho was due to a decrease in TRU waste handling, repackaging, and shipping due to a delay in shipments from WIPP, and the high dose High Integrity Container (HIC) transfer, and sludge treatment. Significant dose was avoided in 2008 due to proficiency improvements for work at the Unirradiated Light Water Breeder Reactor (UL WBR).

\subsubsection{Average Measurable Dose}

The average measurable dose to DOE workers presented in this report for TEDE and CEDE is determined by dividing the collective dose (i.e.,TEDE or CEDE) by the number of individuals with a measurable dose for each dose type. This is one of the key indicators of the overall level of radiation dose received by DOE workers.

The average measurable TEDE is shown in Exhibit 3-3. The average measurable TEDE decreased by $15 \%$ from $0.072 \mathrm{rem}(0.72 \mathrm{mSv})$ in 2007 to $0.061 \mathrm{rem}(0.61 \mathrm{mSv})$ in 2008. The decrease in the average measurable TEDE

Exhibit 3-3:

Average Measurable TEDE, 2004-2008.

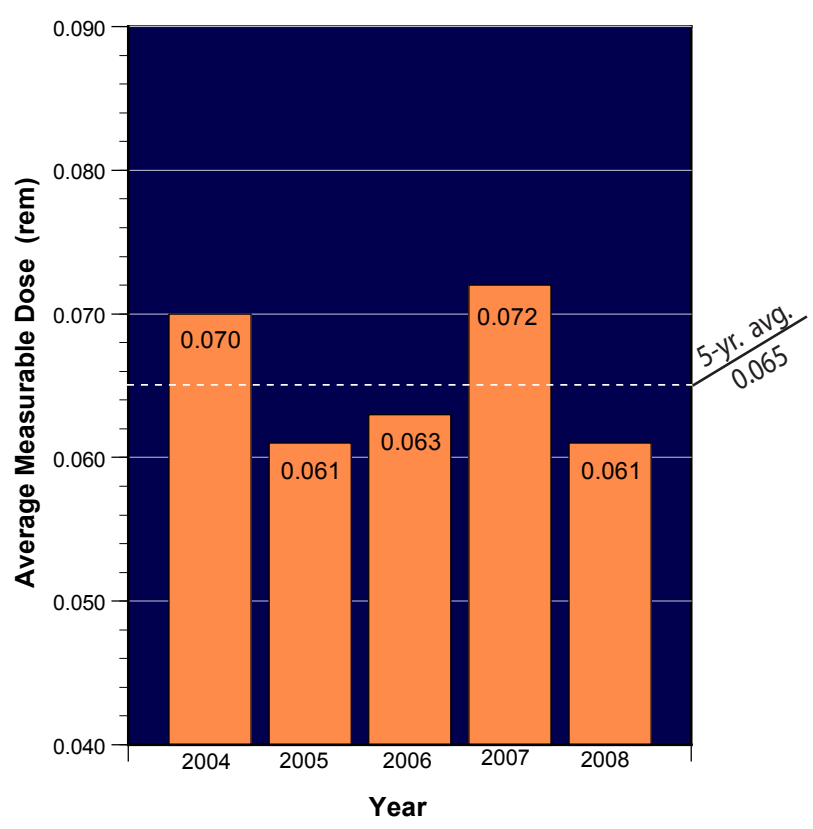

was due primarily to the decrease in the collective TEDE, while the number of individuals with measurable dose increased slightly. While the collective dose and average measurable dose serve as measures of the magnitude of the dose accrued by DOE workers, they do not indicate the distribution of doses among the worker population.

\subsubsection{Dose Distribution}

Exposure data are commonly analyzed in terms of dose intervals to depict the dose distribution among the worker population. Exhibit 3-4 shows the number of individuals in each of 18 different dose ranges.

The number of individuals receiving doses above 0.1 rem $(1 \mathrm{mSv})$ is included to show the number of individuals with doses above the monitoring threshold specified in 10 CFR 835.402(a) and (c). [4]

Exhibit 3-4 shows a decrease in the number of individuals in most dose ranges except for the range measurable to $0.10 \mathrm{rem}(1.0 \mathrm{mSv})$. Ninety-nine percent of the individuals monitored had doses less than $0.25 \mathrm{rem}(2.5 \mathrm{mSv})$. It also shows that the collective TEDE has decreased each year from 2004 to 2008. Note that in 2007, the one exposure in excess of the DOE 5 rems ( $50 \mathrm{mSv}$ ) TEDE limit had a significant impact on the collective dose and the dose distribution. In 2008, it can be seen that the distribution of doses above $0.5 \mathrm{rem}(5 \mathrm{mSv})$ decreased significantly compared with the 2007 distribution. Another way to examine the dose distribution is to analyze the percentage of the dose received above a certain dose value as compared with the total collective dose.

\section{The United Nations' Sources and Effects of Ionizing} Radiation, United Nations Scientific Committee on the Effects of Atomic Radiation (UNSCEAR) 2000 Report to the General Assembly, with Scientific Annexes, Volume I [8], recommends the calculation of a parameter "SR" (previously referred to as CR) to aid in the examination of the distribution of radiation exposure among workers. The parameter SR is defined to be the ratio of the annual collective dose incurred by workers whose annual doses exceed 1.5 rems $(15 \mathrm{mSv})$ to the total annual collective dose.The UNSCEAR report notes that a dose level of 1.5 rems ( $15 \mathrm{mSv})$ may not be useful where doses are consistently lower than this level, and it is recommended that research organizations report SR values lower than 1.5 rems ( $15 \mathrm{mSv})$ where appropriate. For this reason, DOE calculates and tracks the SR at dose levels of 0.100 rem $(1 \mathrm{mSv}), 0.250$ rem $(2.5 \mathrm{mSv}), 0.500$ rem $(5 \mathrm{mSv}), 1.0$ rem $(10 \mathrm{mSv})$, and 2.0 rems $(20 \mathrm{mSv})$. The $\mathrm{SR}$ values shown in 
Exhibit 3-4:

Distribution of TEDE by Dose Range, 2004-2008.

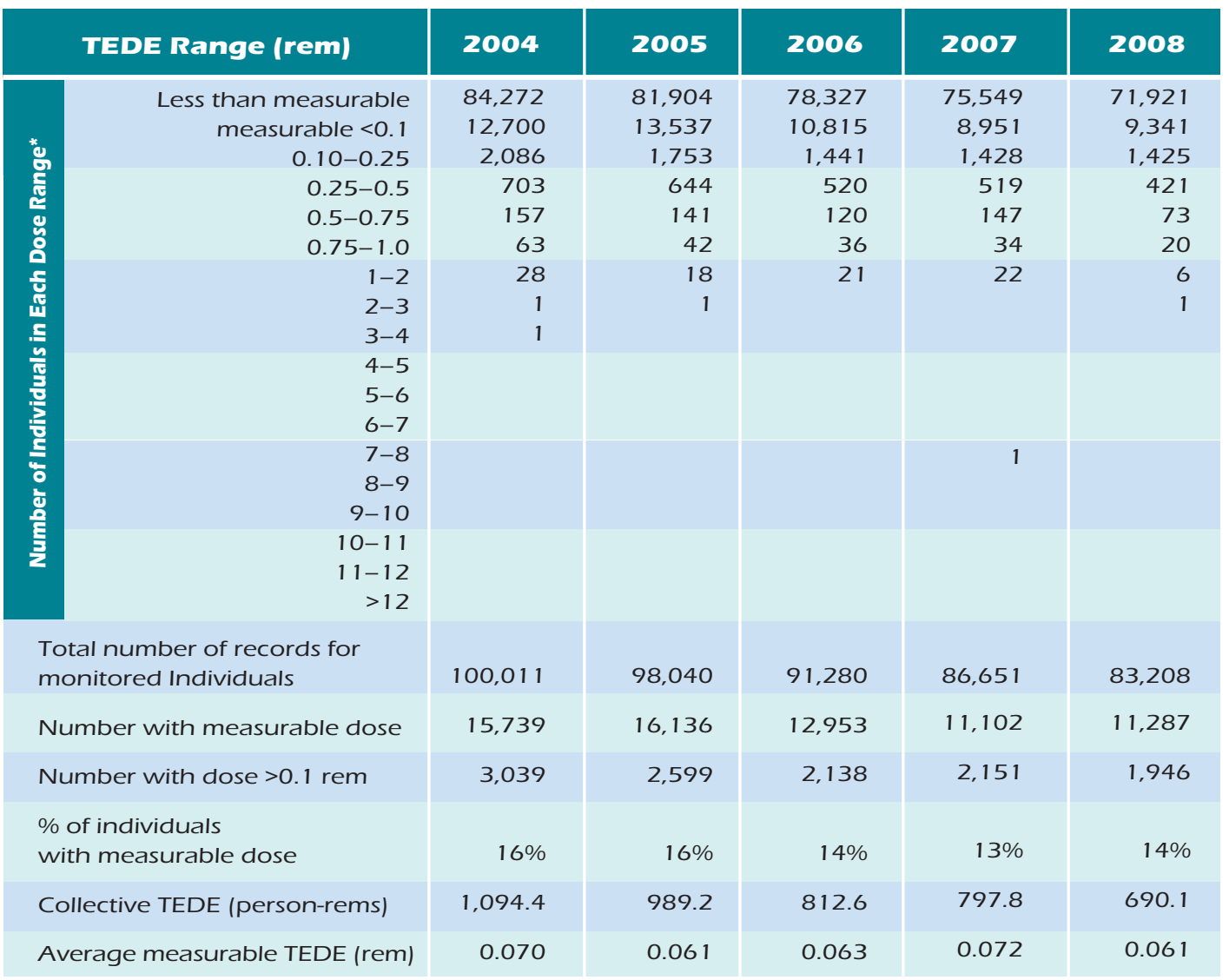

* Individuals with doses equal to the dose value separating the dose ranges are included in the next higher dose range.

Exhibit 3-5 were calculated by summing the TEDE to each individual who received a TEDE greater than or equal to the specified dose level divided by the total collective TEDE. This ratio is presented as a percentage rather than a decimal fraction.

Exhibit 3-5 shows the dose distribution given by percentage of collective TEDE above each of five dose values from $0.1 \mathrm{rem}(1 \mathrm{mSv})$ to 2 rems $(20 \mathrm{mSv})$.This graph facilitates the examination of a property described above that may be used as an indication of effective ALARA programs at DOE: a relatively small percentage of the collective dose accrued in the higher dose ranges. Exhibit 3-5 also shows that each successively higher dose range is responsible for a lower percentage of the collective dose. The percentage of the collective dose received in each dose range increased in 2007 primarily due to the one individual who received a dose above 5 rems from an intake of plutonium at LANL. For 2008, the percentages for all dose ranges decreased to the lowest values within the past 5 years.
Exhibit 3-5:

Percentage of Collective TEDE Above Dose Values During 2004-2008.

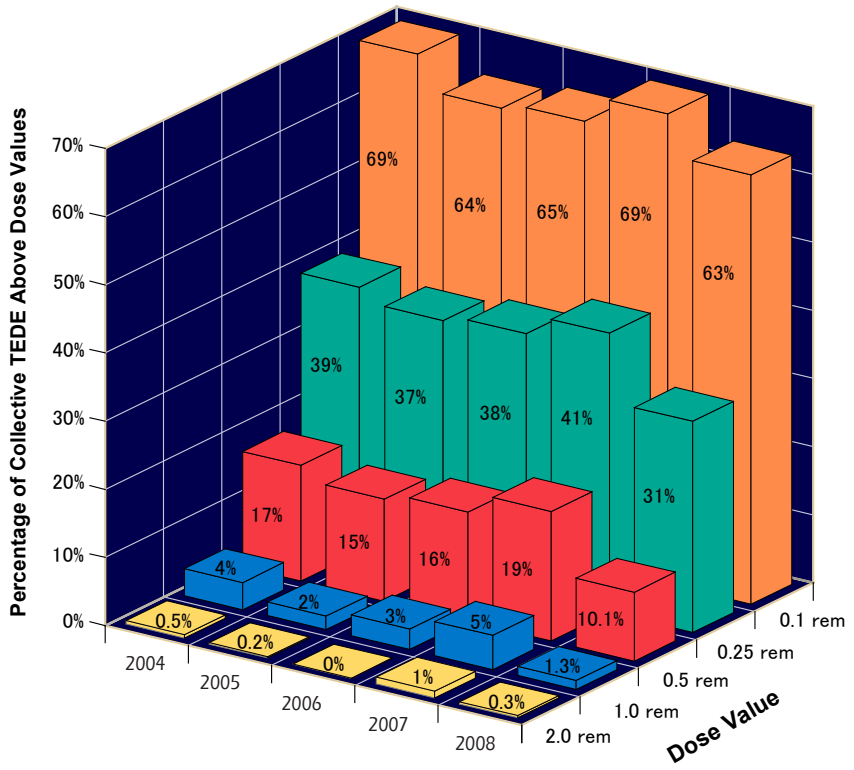




\subsection{Analysis of Individual Dose Data}

The previous analysis is based on aggregate data for DOE. From an individual worker perspective, as well as a regulatory perspective, it is important to closely examine the doses received by individuals in the elevated dose ranges to thoroughly understand the circumstances leading to these doses in the workplace and to better manage and avoid these doses in the future.The following analysis focuses on doses received by individuals that were in excess of the DOE limit (5 rems [50 mSv] TEDE) and the DOE recommended ACL (2 rems [20 mSv] TEDE).

\subsubsection{Doses in Excess of DOE Limit}

Exhibit 3-6 shows the number of doses in excess of the TEDE regulatory limit (5 rems [50 mSv]) from 2004 through 2008. There were no individuals that exceeded 5 rems (50 mSv) TEDE from 2004 to 2006, but one individual received a TEDE in excess of 5 rems $(50 \mathrm{mSv})$ in 2007. In 2008, no individual received a TEDE in excess of 5 rems (50 mSv). However, as described below, there was one individual that received an organ dose in excess of the 50 rems (500 mSv) DOE annual organ dose limit.

\subsubsection{Doses in Excess of Administrative Control Level}

The Radiological Control Standard (RCS) recommends a 2 rems (20 mSv) ACL for TEDE, which should not be exceeded without prior DOE approval.The RCS recommends that each DOE site establish its own more restrictive ACL that would require contractor management

Exhibit 3-6:

Number of Individuals Exceeding 5 rems (TEDE), 2004-2008.

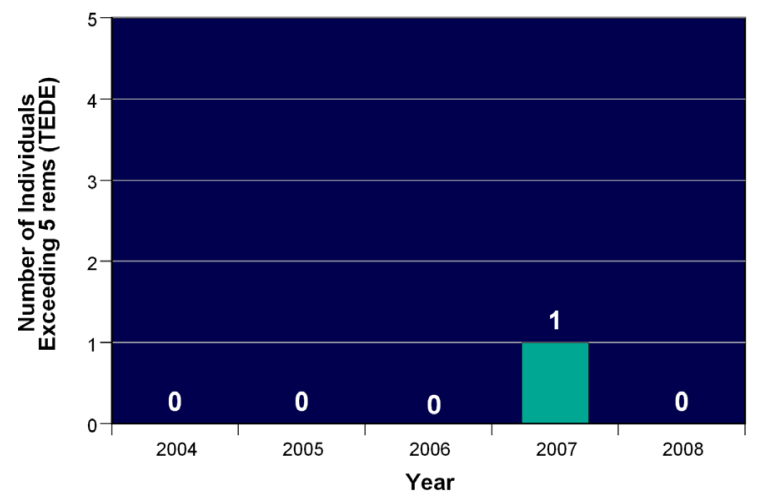

In 2008, no individual received a dose in excess of the 5 rems (50 mSv) TEDE limit. approval to be exceeded.The number of individuals receiving doses in excess of the 2 rems ( $20 \mathrm{mSv}$ ) ACL is a measure of the effectiveness of DOE's radiation protection program.

As shown in Exhibit 3-7, there was one individual who received a TEDE above 2 rems (20 mSv) during 2008.

Exhibit 3-7:

Number of Doses in Excess of the DOE 2 rems ACL, 2004-2008.

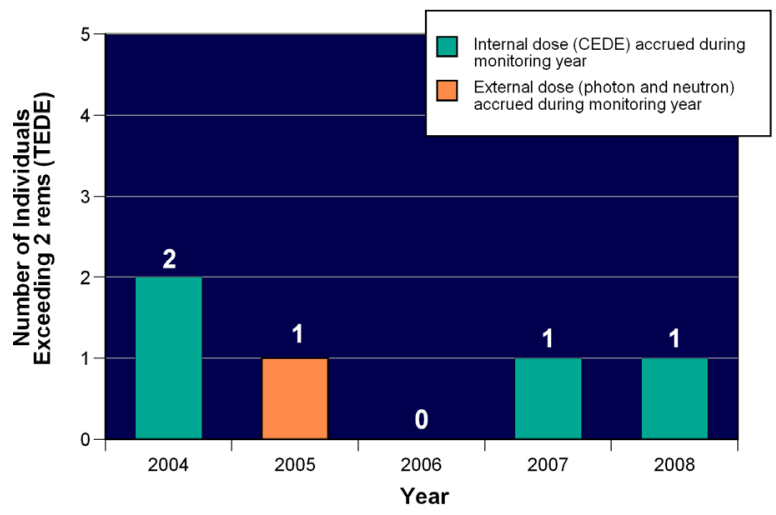

The individual was working at the TA-55 facility at LANL in a glovebox to reduce the size of a contaminated stainless steel item into smaller sample pieces.The task was challenging because it was performed in a glovebox using personal protective equipment (PPE) that included four layers of protective gloves. A small sliver of material punctured the gloves and caused a wound to the operator's finger. As a result, the individual received an internal dose from Pu-239 of 1.8 rems (18 mSv) CEDE and 60 rems (600 mSv) committed dose equivalent (CDE) to the bone surface. Combined with the individual's external exposure, the resultant annual TEDE was 2.106 rems $(210.6 \mathrm{mSv})$, which exceeded the ACL. In addition, the CDE exceeded the 50 rems DOE annual limit to an organ or tissue. Plutonium is primarily retained in the bone surface as it is permanently incorporated into the bone material and delivers a concentrated localized dose from alpha and beta radiation. Since the CDE to the bone surface is calculated over a 50-year period and the $\mathrm{Pu}-239$ stays in the bone surface during this entire period, the bone surface dose is much higher than the dose to other organs and higher than the overall CEDE to the whole body. For further information on this event, see the Occurrence Report NA-LASO-LANL-TA55-2008-0019.

\subsubsection{Internal Depositions of Radioactive Material}

As shown in Exhibit 3-8, some of the highest doses to individuals have been the result of intakes of radioactive 
Exhibit 3-8:

Doses in Excess of DOE Limit, 2004-2008.

\begin{tabular}{|c|c|c|c|c|c|c|c|}
\hline Year & $\begin{array}{l}\text { TEDE } \\
\text { (rem) }\end{array}$ & $\begin{array}{c}\text { DDE } \\
\text { (rem) }\end{array}$ & $\begin{array}{l}\text { CEDE } \\
\text { (rem) }\end{array}$ & $\begin{array}{c}\text { CDE } \\
\text { (rem) }\end{array}$ & Intake Nuclides & Facility Types & Site \\
\hline 2004 & & & & \multicolumn{2}{|c|}{ None reported } & & \\
\hline 2005 & & & & \multicolumn{2}{|c|}{ None reported } & & \\
\hline 2006 & & & & \multicolumn{2}{|c|}{ None reported } & & \\
\hline 2007 & 7.530 & 0 & 7.530 & 130 & Pu-238, Pu-239 & Research, General & LANL \\
\hline 2008 & 2.106 & 0.286 & 1.820 & 60 & Pu-238, Pu-239 & TA-55 Facility & LANL \\
\hline
\end{tabular}

material. For this reason, DOE emphasizes the need to avoid intakes and tracks the number of intakes as a performance measure in this report.

The number of internal depositions of radioactive material (an indicator of worker intakes), collective CEDE, and average measurable CEDE for 2004 to 2008 are shown in Exhibit 3-9. The number of internal depositions decreased by $1 \%$ from 1,237 in 2007 to 1,223 in 2008, while the collective CEDE decreased by $11 \%$.As a result, the average measurable CEDE decreased from 0.053 rem (0.53 mSv) in 2007 to $0.047 \mathrm{rem}(0.47 \mathrm{mSv})$ in 2008 . Note that the 2007 data have been updated to incorporate corrections in the internal dose records reported by Y-12 National Security Complex (Y-12 NSC) in Oak Ridge. Y-12 NSC reports the majority of the internal dose from uranium at DOE and these doses can take a long time to finalize based on bioassay measurement. Adjustments were made for the 2007 uranium intakes in December 2008.
During the past 5 years, there has been one intake from plutonium in excess of 5 rems $(50 \mathrm{mSv})$ TEDE. However, it should be noted that the individual that exceeded 2 rems TEDE also received a CDE to the bone surface of 60 rems, which is in excess of the DOE annual limit for an organ or tissue.

A majority (82\%) of the collective CEDE was from uranium intakes at the Oak Ridge Y-12 NSC during the operation and management of Enriched Uranium Operations facilities at the site. Compared with external dose, relatively few workers receive measurable internal dose, so fluctuations in the number of workers and collective CEDE can occur from year to year.While trend analysis is statistically limited, these values have exhibited an overall decreasing trend over the past 5 years.

Exhibit 3-10 shows the distribution of the internal dose from 2004 to 2008. The total number of individuals with intakes in each dose range is the sum of all records of intake in the subject dose range. Individuals with multiple intakes during the year may be counted more than once.

Exhibit 3-9:

Number of Internal Depositions, Collective CEDE, and Average Measurable CEDE, 2004-2008.

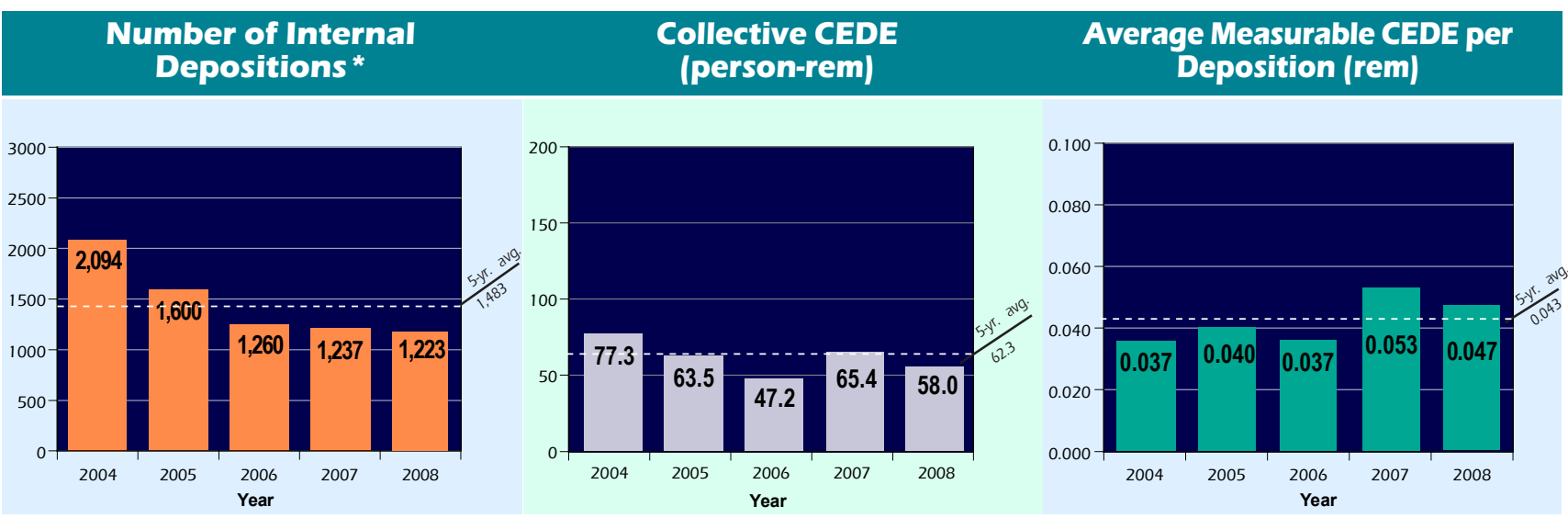

* The number of internal depositions represents the number of internal dose records with positive results reported for each individual. Individuals may have multiple intakes in a year and, therefore, may be counted more than once. 
Exhibit 3-10:

Internal Dose Distribution from Intakes, 2004-2008.

\begin{tabular}{|c|c|c|c|c|c|c|c|c|c|c|c|c|c|}
\hline \multirow[b]{2}{*}{ Year } & \multicolumn{11}{|c|}{ Number of Individuals with CEDE in the Ranges (rem)* } & \multirow{2}{*}{$\begin{array}{l}\text { Total } \\
\text { No. of } \\
\text { Indiv. }\end{array}$} & \multirow{2}{*}{$\begin{array}{c}\text { Total Collective } \\
\text { CEDE } \\
\text { (person-rem) }\end{array}$} \\
\hline & $\begin{array}{c}\text { Meas. } \\
<0.020\end{array}$ & $\begin{array}{l}0.020 \\
0.100\end{array}$ & $\begin{array}{l}0.100 \\
0.250\end{array}$ & $\begin{array}{l}0.250 \\
0.500\end{array}$ & $\begin{array}{l}0.500- \\
0.750\end{array}$ & $\begin{array}{l}0.750 \\
1.000\end{array}$ & $\begin{array}{l}1.0- \\
2.0\end{array}$ & $\begin{array}{l}2.0- \\
3.0\end{array}$ & $\begin{array}{l}3.0 . \\
4.0\end{array}$ & $\begin{array}{l}4.0- \\
5.0\end{array}$ & $>5.0$ & & \\
\hline 2004 & 1,364 & 521 & 184 & 12 & 7 & 3 & 1 & 1 & 1 & & & 2,094 & 77.3 \\
\hline 2005 & 858 & 562 & 156 & 22 & 1 & 1 & & & & & & 1,600 & 63.5 \\
\hline 2006 & 664 & 474 & 106 & 15 & 1 & & & & & & & 1,260 & 47.2 \\
\hline 2007 & 623 & 436 & 151 & 22 & 3 & 1 & & & & & 1 & 1,237 & 65.4 \\
\hline 2008 & 602 & 460 & 131 & 25 & 2 & 2 & 1 & & & & & 1223 & 58.0 \\
\hline
\end{tabular}

*Individuals with doses equal to the dose value separating the dose ranges are included in the next higher dose range.

**Individuals may have multiple intakes in a year and, therefore, may be counted more than once.

Doses below 0.020 rem $(0.20 \mathrm{mSv})$ are shown as a separate dose range, which shows the large number of doses in this low dose range.There was no internal dose above 5 rems (50 mSv) CEDE in 2008.

The internal dose records indicate that the majority of the intakes result in very low doses. In $2008,49 \%$ of the internal dose records were for doses below 0.020 rem $(0.20$ $\mathrm{mSv}$ ). Over the 5-year period, internal doses from intakes accounted for $7 \%$ of the collective TEDE, and $11 \%$ of the individuals who received internal doses were above the monitoring threshold (100 mrem [1 mSv]) specified in 10 CFR 835.402(c). [4]

\subsubsection{Bioassay and Intake Summary Information}

The revised DOE Manual 231.1-1A [6] was issued on March 19,2004 . Reporting of bioassay and intake summary data under the revised DOE Manual 231.1-1A occurred for the first time in 2005. During the past 3 years, urinalysis has been reported as the most common method of bioassay measurement used to determine internal doses to the individuals. Exhibit 3-11 shows the breakdown of bioassay measurements by measurement type.The measurements reported under "in vivo" include measurements taken while the radioactive material is in the body of the monitored person. Examples of in vivo measurements include whole body counts and lung or thyroid counts. The measurements reported in "Other" are for air samples taken in the workplace that are used to calculate the amount of airborne radioactive material taken into the body and the
Exhibit 3-11:
Bioassay Measurements, 2006-2008.

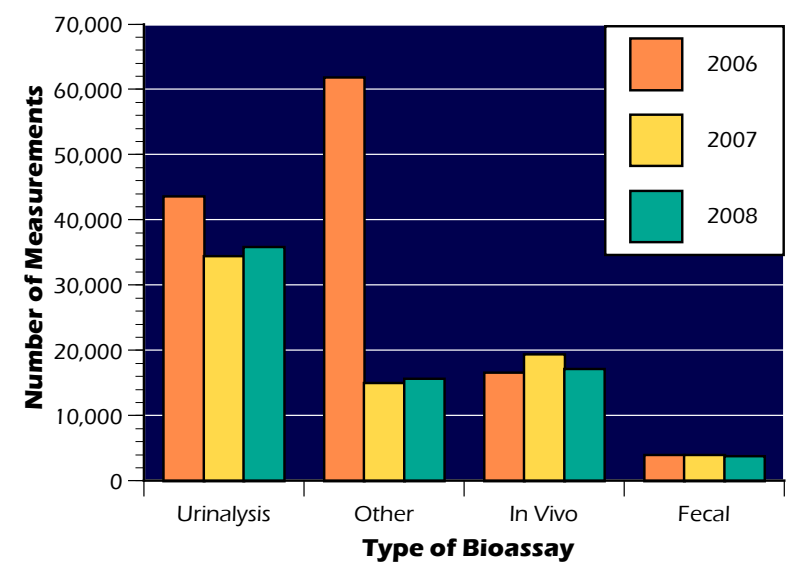

Exhibit 3-12:

Collective CEDE by Radionuclide, 2008.

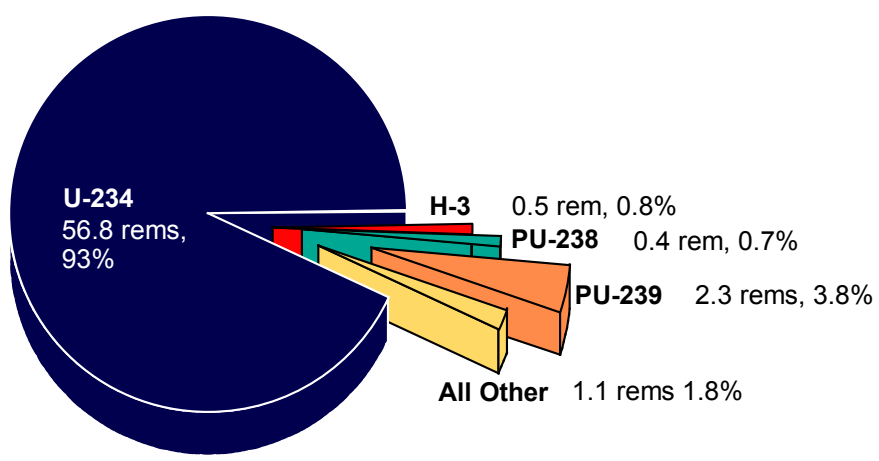


resultant internal dose. Note that the numbers shown are based on the number of measurements taken, not the number of individuals monitored. Individuals may have measurements taken more than once during the year. Seventy-nine percent of the urinalysis measurements were performed at four sites: Oak Ridge Y-12 NSC, SRS, LANL, and Hanford.All of the bioassay measurements reported as "other" were from air sampling reported by Hanford, SRS, and Pantex. The large decrease in the number of "other" bioassay measurements that occurred between 2006 and 2007 was because of the closure of Fernald, which performed a large number of air samples prior to 2007.

Exhibit 3-12 shows the breakdown of the collective CEDE by radionuclide for 2008 . Uranium-234 accounts for the largest percentage of the collective dose, with over $99 \%$ of this dose accrued at the Oak Ridge Y-12 NSC site.

\subsection{Analysis of Site Data}

\subsubsection{Collective TEDE by Site and Other Facilities}

The collective TEDE for 2006 through 2008 for the major DOE sites and operations/field offices is shown graphically in Exhibit 3-13. A list of the collective TEDE and number of individuals with measurable TEDE by DOE sites is shown in Exhibit 3-14. The collective TEDE decreased by $13 \%$ from 798 person-rems (7.98 person-Sv) in 2007 to 690 personrems (6.90 person-Sv) in 2008, with SRS, Idaho, Oak Ridge sites (including East Tennessee Technology Park [ETTP], Y-12 NSC, ORNL, and Oak Ridge Institute for Science and Education [ORISE]), LANL, and Hanford (including the Hanford Site, PNL and ORP) contributing 79\% of the total DOE collective TEDE.

\subsubsection{Changes by Site from 2007 to 2008}

Exhibit 3-15 shows the collective TEDE, the number with a measurable dose, the average measurable TEDE, and the percentage of the collective TEDE delivered above 0.500 rem by site for 2008, as well as the percentage change in these values from the previous year. Some of the largest

Exhibit 3-13:

Collective TEDE by DOE Site for 2006-2008.

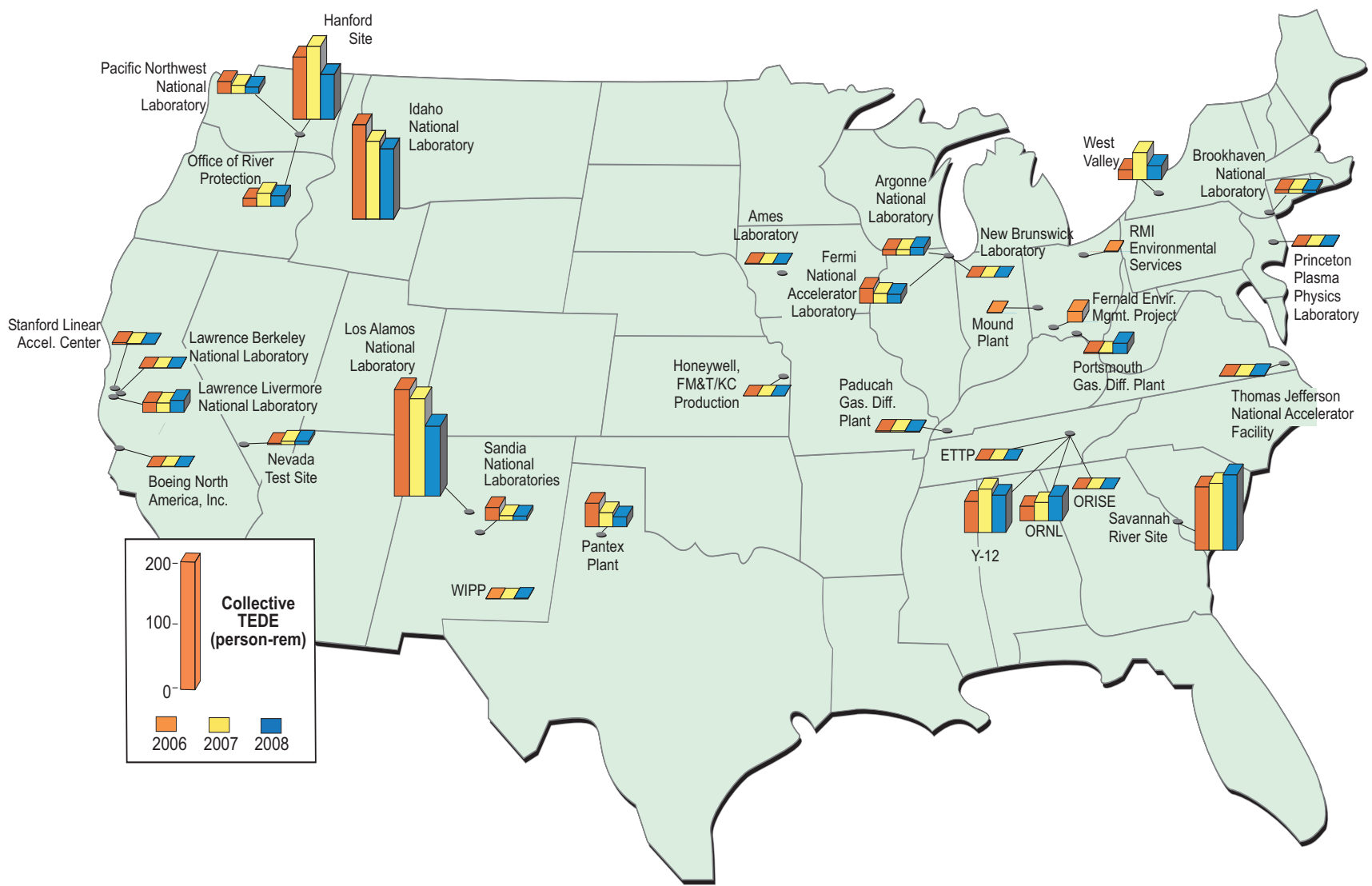




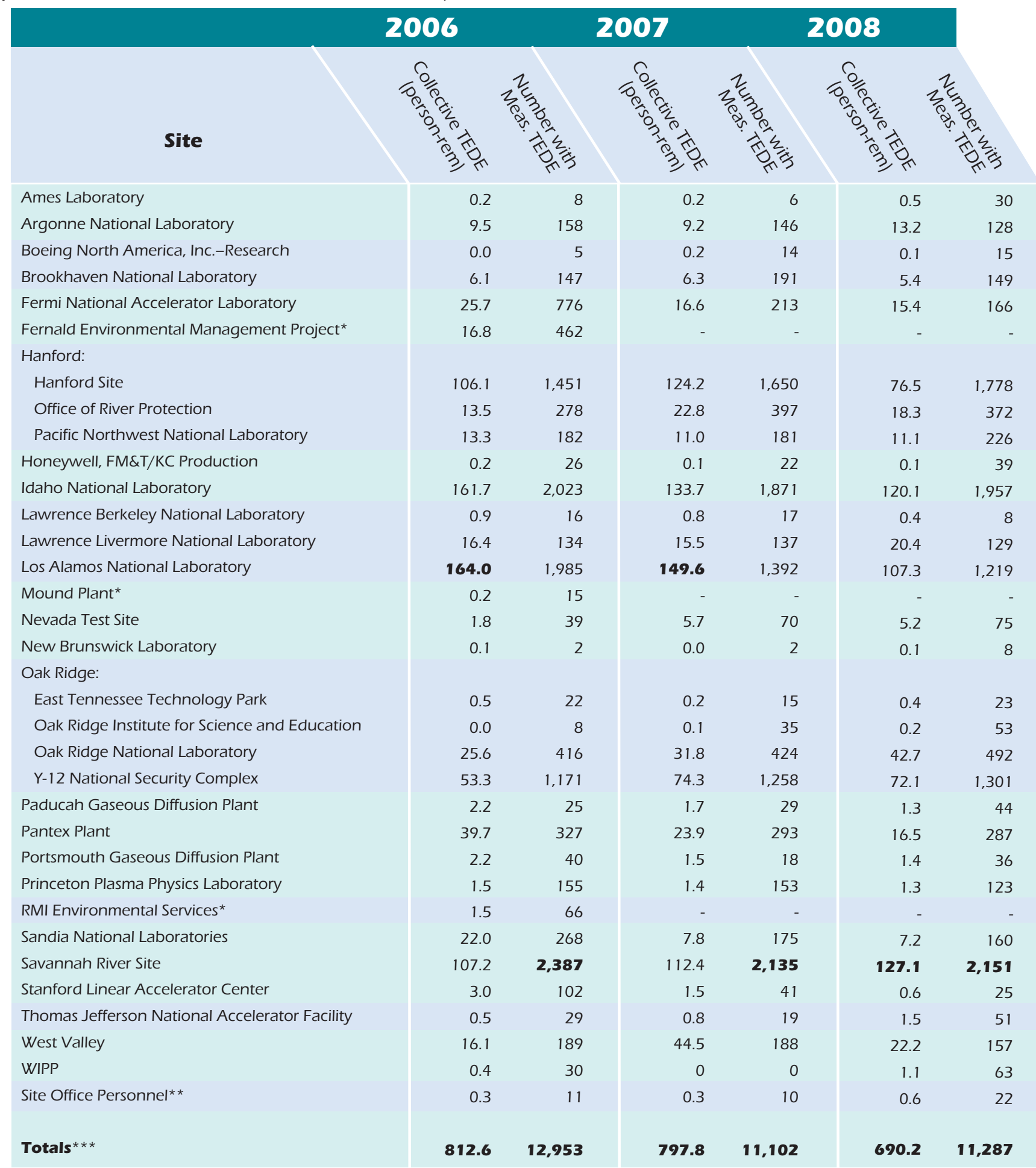

Note: Bold values indicate the greatest value in each column.

*In 2006, Fernald, Mound Plant, and RMI Environmental Services ceased operations.

**Includes site office personnel from Albuquerque, Chicago, Oak Ridge, and Ohio in addition to several smaller facilities not associated with a DOE site.

*** The collective TEDE totals are calculated from the dose records that are reported in millirem while the values shown are rounded to the nearest tenth of a rem. 
Exhibit 3-15:

Site Dose Data, 2008

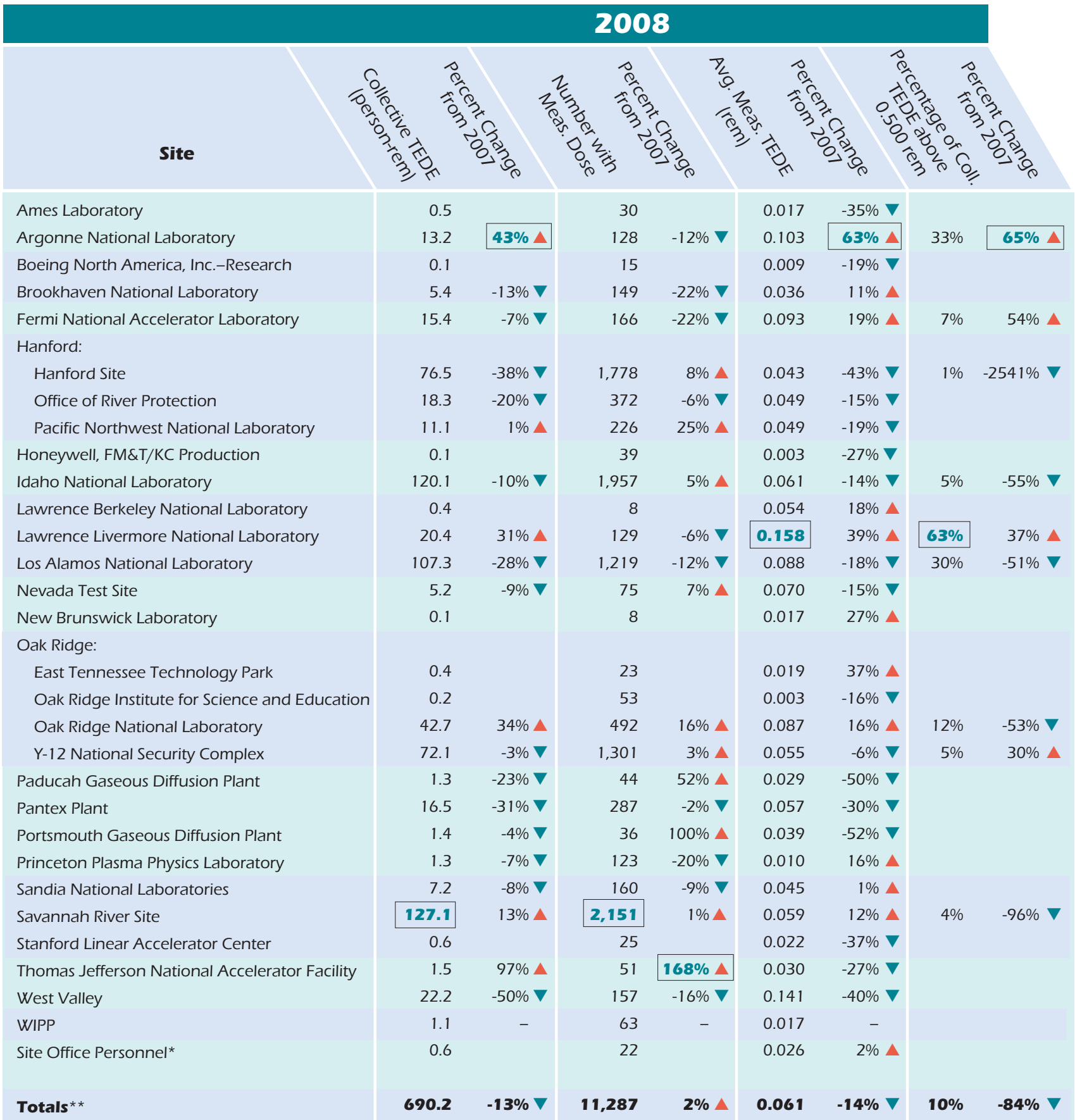

Note: Bold values indicate the greatest value in each column.

The percentage change from the previous year is not shown because it is not meaningful when the site collective dose is less than 1 person-rem (10 person-mSv). *Includes site office personnel from Albuquerque, Chicago, Oak Ridge, and Ohio in addition to several smaller facilities not associated with a DOE site.

** The collective TEDE totals are calculated from the dose records that are reported in millirem while the values shown are rounded to the nearest tenth of a rem. 
percentages of change occur at relatively small facilities where conditions may fluctuate from year to year. The changes that have the most impact in the overall values at DOE occur at sites with a relatively large collective dose in addition to a large percentage change, such as Hanford and Idaho in 2008.

The percentage of the collective TEDE above $0.500 \mathrm{rem}$ is an indicator of the distribution of dose to individuals. A greater fraction of the monitored population is receiving doses above $0.5 \mathrm{rem}$. See section 3.2.5 for more information on the characteristics of the distribution of doses to individuals above a certain dose value.

\subsubsection{Activities Significantly Contributing to Collective Dose in 2008}

In an effort to identify the reasons for changes in the collective dose at DOE, several of the larger sites were contacted to provide information on activities that significantly contributed to the collective dose for 2008. These sites (Savannah River, Idaho, Oak Ridge, Los Alamos, and Hanford) had a collective dose over 100 person-rems and were the top contributors to the collective TEDE in 2008. These sites comprised $79 \%$ of the total collective TEDE at DOE. Three of the sites reported decreases in the collective TEDE, which contributed to a $13 \%$ decrease in the DOE collective TEDE from 798 person-rems (7.98 person-Sv) in 2007 to 690 person-rems (6.90 person-Sv) in 2008. The sites significantly contributing to the collective TEDE in 2008 are shown in Exhibit 3-16, including a description of activities that affected the collective TEDE.

Exhibit 3-16:

Activities Significantly Contributing to Collective TEDE in 2008.

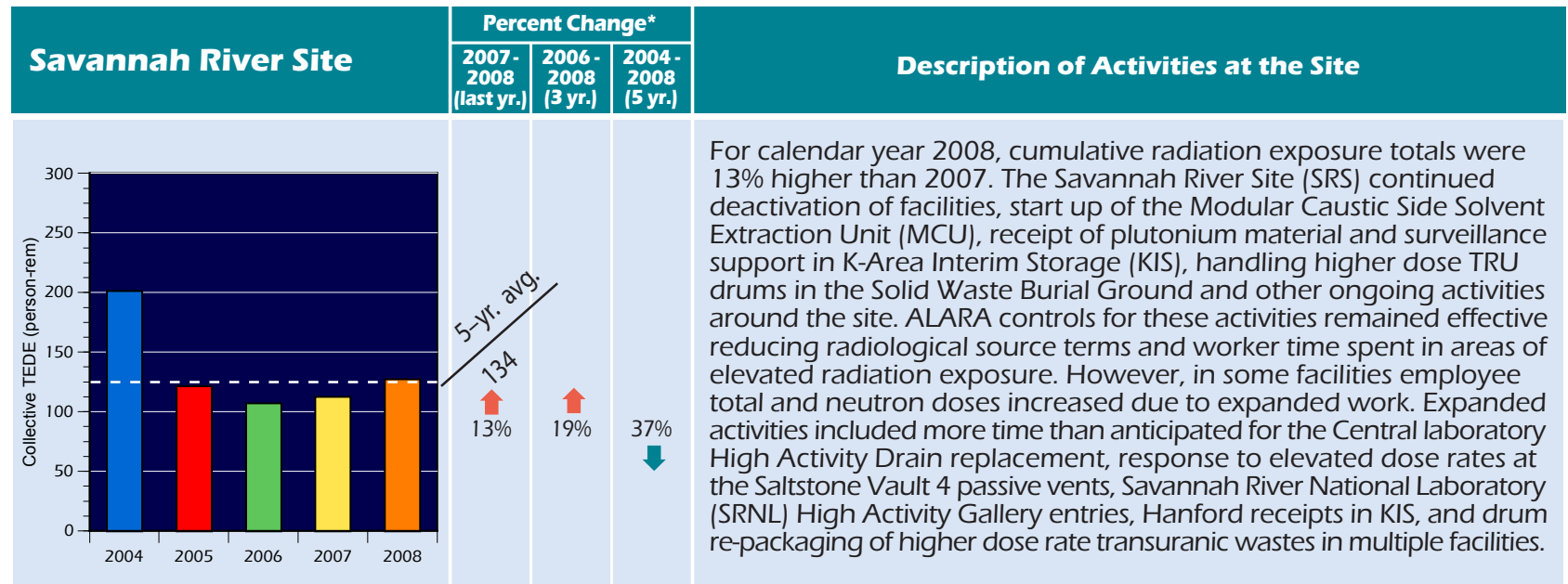

* Up arrows indicate an increase in change. Down arrows indicate a decrease in change. 
Exhibit 3-16 (Continued):

Activities Significantly Contributing to Collective TEDE in 2008.

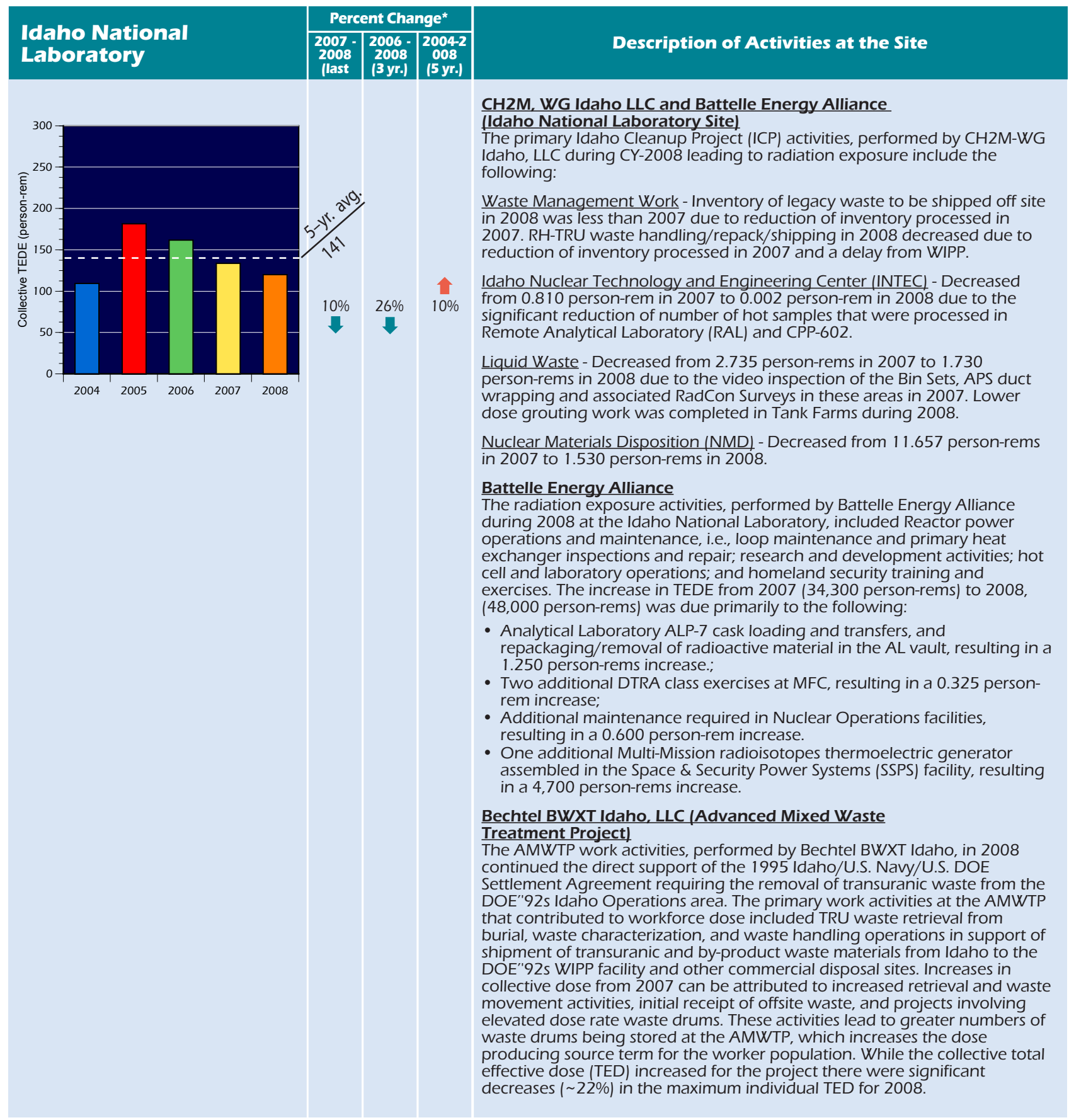

* Up arrows indicate an increase in change. Down arrows indicate a decrease in change. 
Exhibit 3-16 (Continued):

Activities Significantly Contributing to Collective TEDE in 2008.

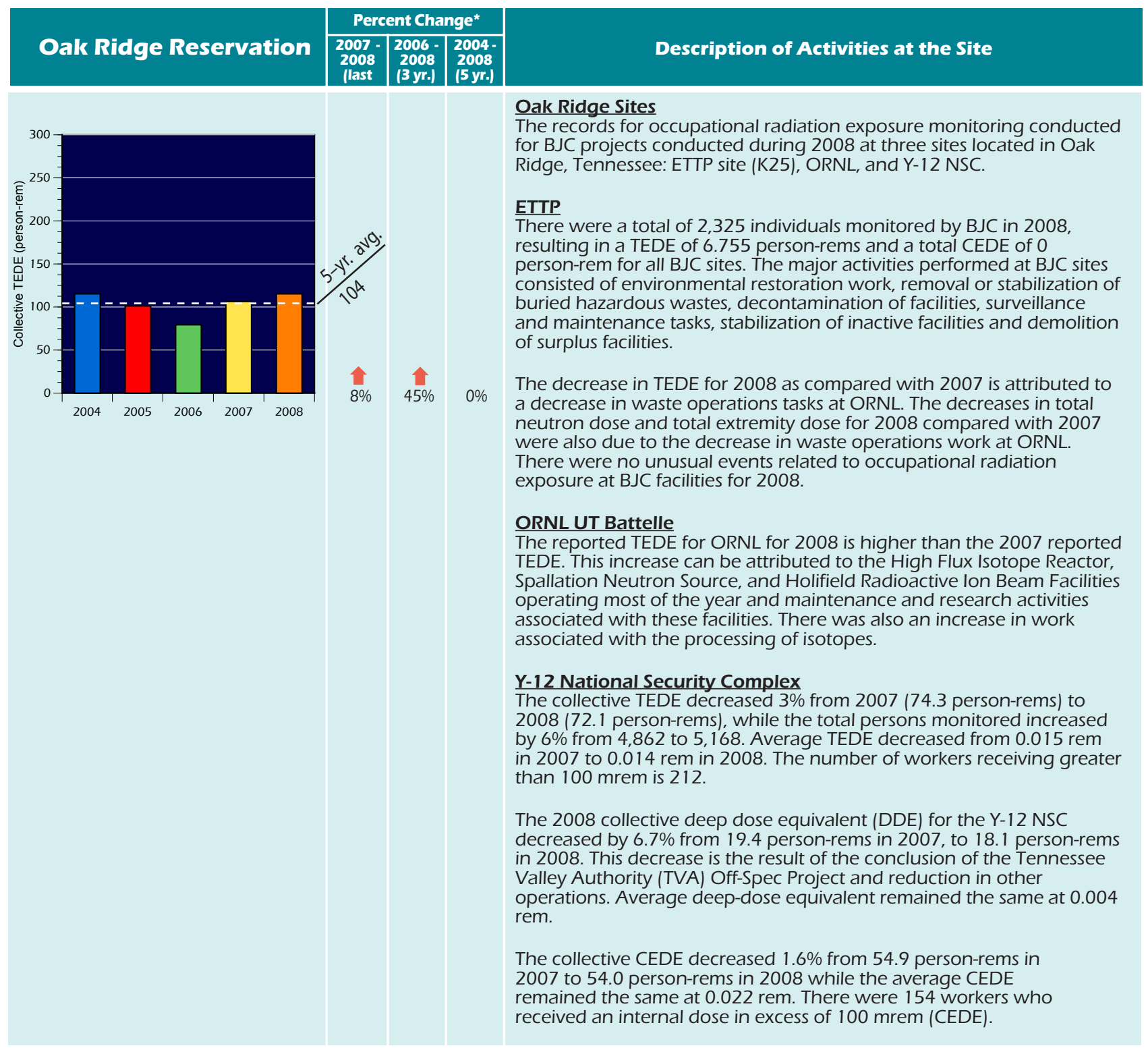

* Up arrows indicate an increase in change. Down arrows indicate a decrease in change. 
Exhibit 3-16 (Continued):

Activities Significantly Contributing to Collective TEDE in 2008.

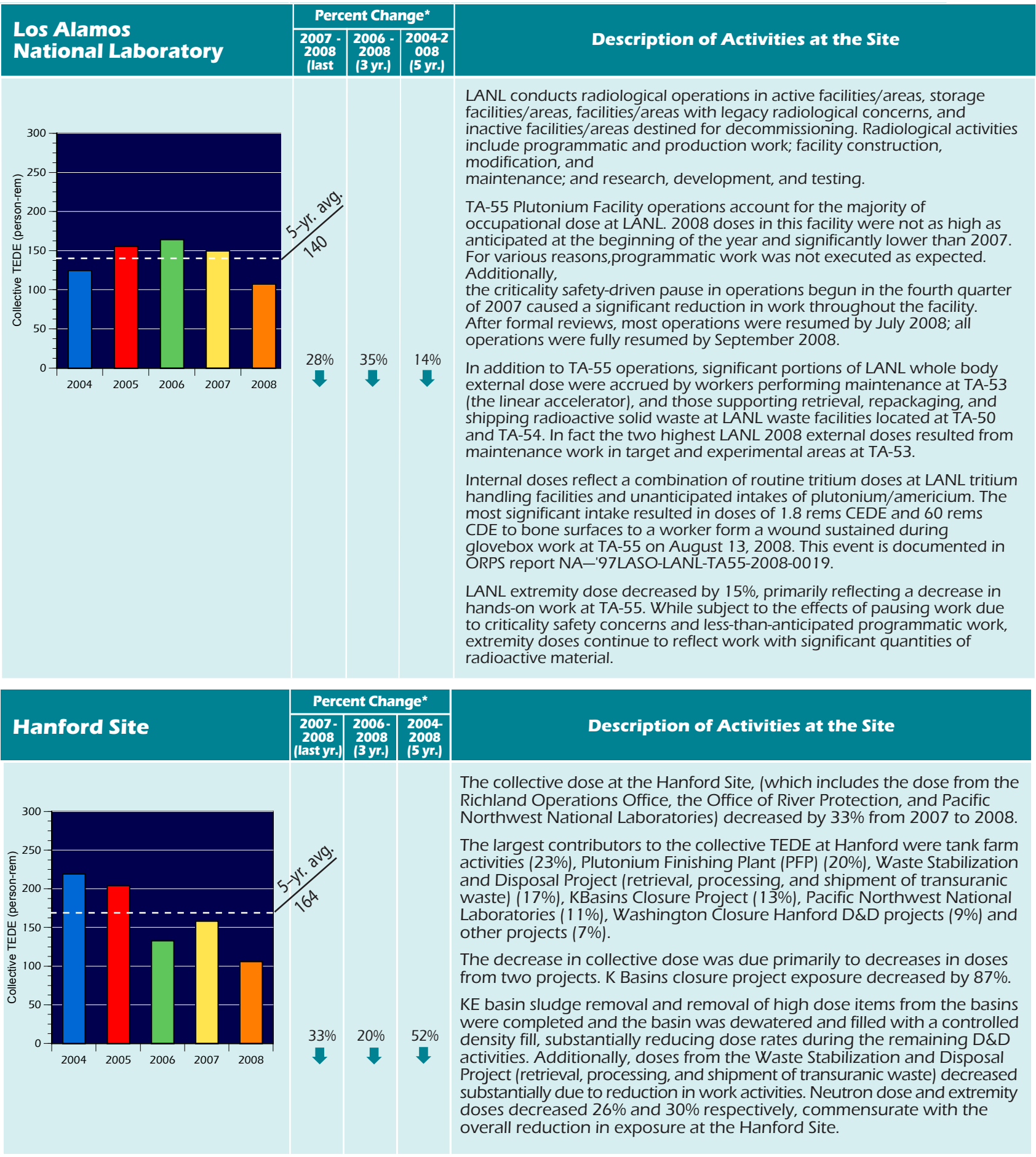

* Up arrows indicate an increase in change. Down arrows indicate a decrease in change. 
In addition to the information provided in Exhibit 3-16, several of the DOE sites provided further information on operations conducted during the monitoring year. DOE Manual 231.1-1A,Appendix G, Section 1, specifies that the sites should provide a description of activities conducted at the site as it relates to the collective radiation exposure received. The following descriptions are excerpts from the transmittal letters from DOE sites that are not among the top contributors to the DOE collective dose in 2008.

\section{Ames Laboratory}

The use of x-ray devices, radiological materials, and remediation of radiological legacy contamination are pathways of exposure at Ames Laboratory. The Laboratory has $16 \mathrm{X}$-ray systems. There are also limited research activities that utilize radioactive materials. In the past year, some laser ablation work using radioactive material and irradiated metals activities were conducted. Depleted uranium electrotransport processes were also conducted.

\section{Argonne National Laboratory}

The collective dose (TEDE) at Argonne was approximately 13,200 person-mrem, up from approximately 9,200 person-mrem the previous year. The Alpha Gamma Hot Cell Facility (AGHCF) was the primary dose contributor in 2008. The Intense Pulsed Neutron Source (IPNS) was shut down at the beginning of the year and only contributed approximately 500 person-mrem to the total.

There were two AGHCF workers with an annual individual dose (TEDE) slightly exceeding 1,000 mrem. The doses at AGHCF were accrued mainly during maintenance periods and campaigns to remove radioactive waste from the hot cell. Other major contributors were site waste management operations and nuclear engineering fuel cladding studies.

\section{Lawrence Berkeley National Laboratory}

The collective total effective dose (TED) at LBNL decreased slightly from 0.770 person-rem in 2007 to 0.429 person-rem in 2008. Eighty-five percent of the collective TED is the result of radiological activities at the Center for Functional Imaging (CFI),specifically those activities associated with new radiopharmaceutical (F-18/C-11) development.

\section{Lawrence Livermore National Laboratory}

Lawrence Livermore National Laboratory (LLNL) is a DOE facility operated by the Lawrence Livermore National
Security, LLC management team (LLNS), which includes Bechtel, the University of California, BWX Technologies, Washington Group, and Battelle. The site serves as a national resource of scientific, technical, and engineering capability with a special focus on national security. LLNL's mission encompasses such areas as strategic defense, energy, the environment, biomedicine, technology transfer, education, counter-terrorism, and emergency response. Support of these operations requires the use of a wide range of radiation-producing devices (e.g., x-ray machines, accelerators, electron-beam welders) and radioactive material.The types of radioactive materials range from tritium to transuranics; the quantities range from nanocuries (i.e., normal environmental background values) to kilocuries.

The 2008 total collective TEDE of 20,356 mrem reflects an increase from the 2007 total collective TEDE of 15,413 mrem and represents a return of normal operations in the Plutonium Facility at LLNL. Doses for 2008 are as expected.

\section{Paducah Gaseous Diffusion Plant}

The exposure information for activities at the Paducah site covers Paducah Remediation Services, LLC (PRS) activities performed under the DOE contract scope for environmental remediation, facility decontamination, and final assessment of buildings and areas at the site. The major activities performed at PRS sites consisted of environmental restoration work, decontamination of facilities, stabilization of inactive facilities, and demolition of surplus facilities.

\section{Pantex Plant}

The DOE/National Nuclear Security Administration (NNSA) Pantex Plant is the nation's only facility for assembly and disassembly of nuclear explosives. The operations that contribute the majority of the dose to Pantex Plant workers are operations that expose them to large numbers of bare weapon pits (the pits contain significant quantities of Special Nuclear Materials). These operations include nuclear explosive assembly/ disassembly operations, weapon dismantlement programs, life-extension programs, Special Nuclear Material Component Re-qualification, and Special Nuclear Material Staging.

The total population dose to Pantex Plant workers decreased by $31 \%$ in 2008 compared with 2007 and was the lowest level in the previous 10 years of Pantex operations. The decrease was due to variations in the specific types and quantities of production work 
performed by B\&W Pantex and process improvements. No one exceeded 2 rems TED in 2008.

\section{Princeton Plasma Physics Laboratory}

The primary source for exposure during the past monitoring year was due to the continuing National Compact Stellarator Experiment (NCSX) construction activities in the old Tokamak Fusion Test Reactor (TFTR) test cell, renamed the NCSX Coil Winding Facility. This area contains components and materials that were activated during TFTR operations and were not removed during the D\&D effort. The collective dose was lower than the previous year due to a longer than expected maintenance period for NSTX.

\section{Stanford Linear Accelerator Center}

The Stanford Linear Accelerator Center (SLAC) program centers around experimental and theoretical research in elementary particle physics using accelerated electron beams and a broad program of research in atomic and solid-state physics, chemistry, and biology using synchrotron radiation from accelerated electron beams. There is also an active program in the development of accelerators, RF power sources, detectors, and new sources and instrumentation for synchrotron radiation research.The main instrument of research is the $3.2-\mathrm{km}$ linear accelerator (LINAC), which can generate highintensity beams of electrons and positrons up to $50 \mathrm{GeV}$. The Positron-Electron Project (PEP) storage ring is about 800 meters in diameter.While the original PEP program was completed in 1990, the storage ring has since been upgraded to serve as an Asymmetric B Factory (known as PEP-II) to study the $\mathrm{B}$ meson, utilizing the BaBar detector. PEP-II and the BaBar facilities were permanently shut down in April 2008. Replacing PEP-II and Babar programs, the Linac Coherent Light Source (LCLS) will be the world's first X-ray free electron laser (FEL) when it becomes fully operational in 2009. LCLS will use the last kilometer of the SLAC LINAC. LCLS electron beamlines have been commissioned in early 2009 and the photon beamlines will be commissioned starting in July 2009. Another facility, the Stanford Synchrotron Radiation Laboratory (SSRL), has a smaller storage ring, the Stanford Positron-Electron Asymmetric Ring (SPEAR3), a separate, shorter LINAC , and a booster ring for injecting accelerated beams of electrons into SPEAR3.The FEL and synchrotron light generated by the LCLS and SPEAR3 storage ring are used to perform experiments in various fields. The Klystron Test Laboratory (KTL) manufactures all the klystrons used in SLAC accelerators, as well as novel structures and components for future accelerators; it supports low-level and high-level RF operations of SLAC accelerators; and it operates a 70-MeV X-band research accelerator and laser facility capable of producing subpicosecond beam bunches. SLAC is also host of the International Linear Collider (ILC) test facilities, including the Next Linear Collider Test Accelerator (NLCTA).

Compared with the previous 2007 collective TED (1,453 person-mrem), the 2008 collective TED (560 personmrem) is about $40 \%$ of the value for 2007. This decrease in collective TED for calendar year (CY)2008 is mainly associated with the shutdowns of PEP-II and BaBar operations. As mentioned previously, PEP-II and BaBar operations ended in April 2008; thus, the beams from LINAC Sectors 0 -19, including associated klystrons, have been turned off since then. A review of the Radiological Work Permit (RWP) program in 2008 also shows no significant work involving elevated personal exposures. Thus, the collective dose reduction in 2008 was in line with less work activities conducted in radiological areas, especially in high radiation areas and contamination areas during 2008.

\section{Waste Isolation Pilot Plant}

The collective TEDE for the Waste Isolation Pilot Plant (WIPP) for the calendar year 2008 is 1.069 rems. This value reflects a decrease of 0.659 rem from the calendar year 2007. All doses received were from routine activities associated with the disposal of transuranic waste.

\section{West Valley}

Two major projects of dose concern continue to be the D4 Projects (Decommissioning, Decontamination, Dismantlement, and Demolition) and Waste Management. D4 activities included Decontamination \& Decommissioning work in extraction and support cells in preparation for being declared "Demolition-Ready." Waste Management activities included waste processing and shipping for disposal.Waste Management was also involved in modifying facilities to accommodate the remaining waste to be processed.

The 2008 collective TEDE of 22.181 person-rems is approximately $50 \%$ lower than the 2007 collective TEDE of 44.499 person-rems. This decrease was due primarily to completion of several long-term tasks that accrued a large amount of personnel dose. 
Exhibit 3-17:

Program Office Dose Data, 2008.

\begin{tabular}{|c|c|c|c|c|c|c|}
\hline Program Office & $\begin{array}{c}\text { Collective } \\
\text { TEDE } \\
\text { (person-rem) }\end{array}$ & $\begin{array}{c}\text { Percent } \\
\text { Change } \\
\text { from } 2007\end{array}$ & $\begin{array}{l}\text { Number } \\
\text { with Meas. } \\
\text { Dose }\end{array}$ & $\begin{array}{l}\text { Percent } \\
\text { Change } \\
\text { from } 2007\end{array}$ & $\begin{array}{l}\text { Avg. Meas. } \\
\text { TEDE } \\
\text { (rem) }\end{array}$ & $\begin{array}{l}\text { Percent } \\
\text { Change } \\
\text { from } 2007\end{array}$ \\
\hline \multicolumn{7}{|c|}{ Office of Environmental Management (EM) } \\
\hline Boeing & 0.1 & & 15 & & 0.009 & $-19 \% \nabla$ \\
\hline ETTP & 0.4 & & 23 & & 0.019 & $37 \%$ \\
\hline Hanford Site & 76.5 & $-38 \% \nabla$ & 1,778 & $8 \% \triangle$ & 0.043 & $-43 \% \nabla$ \\
\hline Idaho & 41.9 & $-11 \% \Delta$ & 740 & $10 \%$ & 0.057 & $-20 \% \nabla$ \\
\hline ORNL & 13.5 & $0 \%$ & 139 & $-1 \% \nabla$ & 0.097 & $1 \%$ \\
\hline ORP & 18.3 & $-20 \% \nabla$ & 372 & $-6 \% \nabla$ & 0.049 & $-15 \% \nabla$ \\
\hline Paducah & 1.3 & $-23 \% \nabla$ & 44 & $52 \%$ & 0.029 & $-50 \% \nabla$ \\
\hline Portsmouth & 1.4 & $-4 \% \nabla$ & 36 & $100 \%$ & 0.039 & $-52 \% \nabla$ \\
\hline Savannah River & 127.1 & $13 \% \Delta$ & 2,151 & $1 \%$ & 0.059 & $12 \%$ \\
\hline Site Office Personnel & 0.5 & & 14 & & 0.033 & $17 \% \Delta$ \\
\hline West Valley & 22.2 & $-50 \% \nabla$ & 157 & $-16 \% \nabla$ & 0.141 & $-40 \% \nabla$ \\
\hline WIPP & 1.1 & - & 63 & - & 0.017 & - \\
\hline EM Totals* & 304.2 & $-17 \% \nabla$ & 5,532 & $5 \%$ & 0.055 & $-21 \% \nabla$ \\
\hline \multicolumn{7}{|c|}{ National Nuclear Security Administration (NNSA) } \\
\hline Honeywell, FM\&T & 0.1 & & 39 & & 0.003 & $-27 \% \nabla$ \\
\hline LANL & 107.3 & $-28 \% \nabla$ & 1,219 & $-12 \% \nabla$ & 0.088 & $-18 \% \nabla$ \\
\hline LLNL & 20.4 & $31 \%$ & 129 & $-6 \% \nabla$ & 0.158 & 39\% \\
\hline NTS & 5.2 & $-9 \% \nabla$ & 75 & $7 \% \triangle$ & 0.070 & $-15 \% \nabla$ \\
\hline Pantex & 16.5 & $-31 \% \nabla$ & 287 & $-2 \% \nabla$ & 0.057 & $-30 \% \nabla$ \\
\hline SNL & 7.2 & $-8 \% \nabla$ & 160 & $-9 \% \nabla$ & 0.045 & $1 \%$ \\
\hline Site Office Personnel & 0.1 & & 5 & & 0.016 & \\
\hline $\mathrm{Y}-12$ & 72.1 & $-3 \% \nabla$ & 1,301 & $3 \%$ & 0.055 & $-6 \% \nabla$ \\
\hline NNSA Totals* & 228.8 & $-17 \% \nabla$ & 3,215 & $-4 \% \nabla$ & 0.071 & $-14 \% \nabla$ \\
\hline \multicolumn{7}{|c|}{ Office of Nuclear Energy, Science and Technology (NE) } \\
\hline Idaho & 78.1 & $-10 \% \nabla$ & 1,217 & $1 \% \Delta$ & 0.064 & $-11 \% \nabla$ \\
\hline NE Totals* & 78.1 & $-10 \% \nabla$ & 1,217 & $1 \%$ & 0.064 & $-11 \% \nabla$ \\
\hline \multicolumn{7}{|l|}{ Office of Science (SC) } \\
\hline Ames & 0.5 & & 30 & & 0.017 & $-35 \% \nabla$ \\
\hline ANL & 13.2 & $43 \% \triangle$ & 128 & $-12 \% \nabla$ & 0.103 & $63 \%$ \\
\hline $\mathrm{BNL}$ & 5.4 & $-13 \% \nabla$ & 149 & $-22 \% \nabla$ & 0.036 & $11 \% \triangle$ \\
\hline Fermi & 15.4 & $-7 \% \nabla$ & 166 & $-22 \%$ & 0.093 & $19 \%$ \\
\hline LBNL & 0.4 & & 8 & & 0.054 & $18 \%$ \\
\hline New Brunswick & 0.1 & & 8 & & 0.017 & $27 \%$ \\
\hline ORISE & 0.2 & & 53 & & 0.003 & $-16 \% \nabla$ \\
\hline ORNL & 29.2 & $60 \%$ & 353 & $25 \% \triangle$ & 0.083 & $29 \%$ \\
\hline PNNL & 11.1 & $1 \%$ & 226 & $25 \%$ & 0.049 & $-19 \% \nabla$ \\
\hline PPPL & 1.3 & $-7 \% \nabla$ & 123 & $-20 \% \nabla$ & 0.010 & $16 \%$ \\
\hline Site Office Personnel & 0.0 & & 3 & & 0.005 & \\
\hline SLAC & 0.6 & & 25 & & 0.022 & $-37 \% \nabla$ \\
\hline TJ Nat'I Accel & 1.5 & $97 \%$ & 51 & $168 \% \triangle$ & 0.030 & $-27 \% \nabla$ \\
\hline SC Totals* & 78.9 & $20 \% \triangle$ & 1,323 & $3 \%$ & 0.060 & $17 \% \triangle$ \\
\hline
\end{tabular}

Note: Bold values indicate the greatest value in each column section. The percentage change from the previous year is not shown because it is not meaningful when the site collective dose is less than 1 person-rem (10 person-mSv).

*The collective TEDE totals are calculated from the dose records that are reported in millirem while the values shown are rounded to the nearest tenth of a rem. 


\subsubsection{Summary by Program Office}

DOE has divided the responsibility of managing its missions among specific program offices. The various DOE sites support different functions and therefore fall under the authority and management of separate program offices. It should be noted that several of the DOE sites fall under multiple program offices. However, the sites are not required to report radiation exposure by program office, so the exact contribution from each cannot be determined. In these instances, the site is shown under one program office but may have significant portions of the dose from other offices. Exhibit 3-17 shows the number of individuals with measurable dose, the collective TEDE, and the average measurable TEDE by DOE program office.The Office of Environmental Management (EM) and the NNSA account for the largest percentages of the collective dose $(42 \%$ and $33 \%$, respectively). EM works to mitigate the risks and hazards posed by the legacy of nuclear weapons production and research. NNSA is responsible for the management and security of the nation's nuclear weapons, nuclear nonproliferation, and naval reactor programs, as well as responding to radiological emergencies and the transportation of nuclear weapons and special nuclear materials. In general, the missions of EM and NNSA require more interaction and activities involving radioactive materials. These offices account for nearly $76 \%$ of the collective dose at DOE.

The primary sites contributing to the collective TEDE at EM are Hanford,SRS, and Idaho. For NNSA, the primary contributors are LANL and Y-12 NSC. For the Office of Nuclear Energy, Science and Technology (NE), the primary contributor is Idaho.

Exhibit 3-18:

Dose Distribution of Transient Workers, 2004-2008.

\begin{tabular}{|c|c|c|c|c|c|c|}
\hline \multicolumn{2}{|c|}{ Dose Ranges (TEDE in rem) } & 2004 & 2005 & 2006 & 2007 & 2008 \\
\hline \multirow{12}{*}{$\frac{y}{\frac{y}{d}}$} & Less than measurable dose & 1,917 & 2,067 & 1.888 & 2,182 & 2,085 \\
\hline & Measurable $<0.1$ & 439 & 715 & 412 & 388 & 430 \\
\hline & $0.10-0.25$ & 52 & 79 & 24 & 51 & 43 \\
\hline & $0.25-0.5$ & 9 & 13 & 9 & 8 & 9 \\
\hline & $0.5-0.75$ & 4 & 3 & 4 & & \\
\hline & $0.75-1.0$ & & 2 & 3 & & 1 \\
\hline & $1.0-2.0$ & 1 & 1 & 2 & & \\
\hline & Total number of individuals monitored * & 2,422 & 2,880 & 2,342 & 2,629 & 2,568 \\
\hline & Number with measurable dose & 505 & 813 & 454 & 447 & 483 \\
\hline & $\%$ with measurable dose & $21 \%$ & $28 \%$ & $19 \%$ & $17 \%$ & $19 \%$ \\
\hline & Collective TEDE (person-rem) & 25.609 & 39.757 & 25.532 & 22.111 & 21.410 \\
\hline & Average measurable TEDE (rem) & 0.051 & 0.049 & 0.056 & 0.049 & 0.044 \\
\hline \multirow{4}{*}{$\begin{array}{l}\text { 풍 } \\
0 \\
0\end{array}$} & $\begin{array}{l}\text { Total number of records for monitored } \\
\text { individuals }\end{array}$ & 100,011 & 98,040 & 91,280 & 86,651 & 83,208 \\
\hline & Number with measurable dose & 15,739 & 16,136 & 12,953 & 11,102 & 11,287 \\
\hline & $\%$ of total monitored who are transient & $2.4 \%$ & $2.9 \%$ & $2.6 \%$ & $3.0 \%$ & $3.0 \%$ \\
\hline & dose who are transient & $3.2 \%$ & $5.0 \%$ & $3.5 \%$ & $4.0 \%$ & $4.3 \%$ \\
\hline
\end{tabular}

* Total number of individuals represents the number of individuals monitored and not the number of records. 


\subsection{Transient Individuals}

Transient individuals, or transients, are defined as individuals who are monitored at more than one DOE site during the calendar year. For the purpose of this report, a DOE site is defined as a geographic location. During the year, some individuals performed work at multiple sites and, therefore, had more than one monitoring record reported to the repository. In addition, some individuals transferred from one site to another. This section presents information on transient individuals to determine the extent to which individuals traveled from site to site and to examine the doses received by these individuals. Exhibit 3-18 shows the dose distribution and total number of transient individuals from 2004 to 2008 . Over the past 5 years, the records of transient individuals have averaged $2.8 \%$ of the total records for all monitored individuals at DOE. These individuals received, on an average, $3 \%$ of the collective dose. The collective dose for transients decreased by $3 \%$ from 22.1 person-rems (221 person-mSv) in 2007 to 21.4 person-rems (214 person-mSv) in 2008. The average measurable TEDE decreased from 0.049 rem (0.49 mSv) in 2007 to $0.044 \mathrm{rem}(0.44 \mathrm{mSv})$ in 2008. Since 1993 , these parameters have remained relatively constant, even though DOE has become extensively involved in D\&D activities and other types of operations.

\subsection{Historical Data}

\subsubsection{Prior Years}

In order to analyze recent radiation exposure data in the context of the history of radiation exposure at DOE, it is useful to include information prior to the past 5 years as presented in this report. For this reason, Exhibits 3-19 and 3-20 are presented to show a summary of occupational exposures back to 1974, when the Atomic Energy Commission (AEC) split into the Nuclear Regulatory Commission and the Energy Research and Development Administration (ERDA), which subsequently became DOE. Exhibits 3-19 and 3-20 show the collective dose, average measurable dose, and number of workers with a measurable dose from 1974 to 2008. As can be seen from the graphs, all three parameters decreased dramatically between 1986 and 1993. The main reasons for this large decrease were the shutdown of facilities within the weapons complex and the end of the Cold War era, which shifted the DOE mission from weapons production to shutdown, stabilization, and D\&D activities.

\subsubsection{Historical Data Collection}

In section 3.7 of the 2000 and 2001 annual reports on occupational exposure, information was presented on historical data that had been collected to date. Sites were requested by DOE to voluntarily provide historical exposure data. No additional sites have reported historical data during the year 2008.

Sites that have not yet reported historical dose records are encouraged to contact Ms. Nirmala Rao at DOE (see section 1.2) to obtain further information on reporting these records. This is a request to voluntarily report historical data (records prior to 1987) that are available in electronic form or in whatever format that is most convenient for the site. The data will be stored as reported in REMS, and wherever possible, data will be extracted and loaded into the REMS database for analysis and retrieval. For detailed analysis, read section 3.7 of the 2000 report.

Sites that have voluntarily reported historical data are as follows:

Fernald Environmental Management Project
Hanford Site
Idaho National Laboratory
Kansas City Plant
Lawrence Berkeley National Laboratory
Lawrence Livermore National Laboratory
Nevada Test Site
Oak Ridge K-25 Site
Pantex Plant
$>$ Portsmouth Gaseous Diffusion Plant
$>$ Socky Flats Environmental Technology Site
Sandia National Laboratories


Exhibit 3-19:

Collective Dose and Average Measurable Dose, 1974-2008.

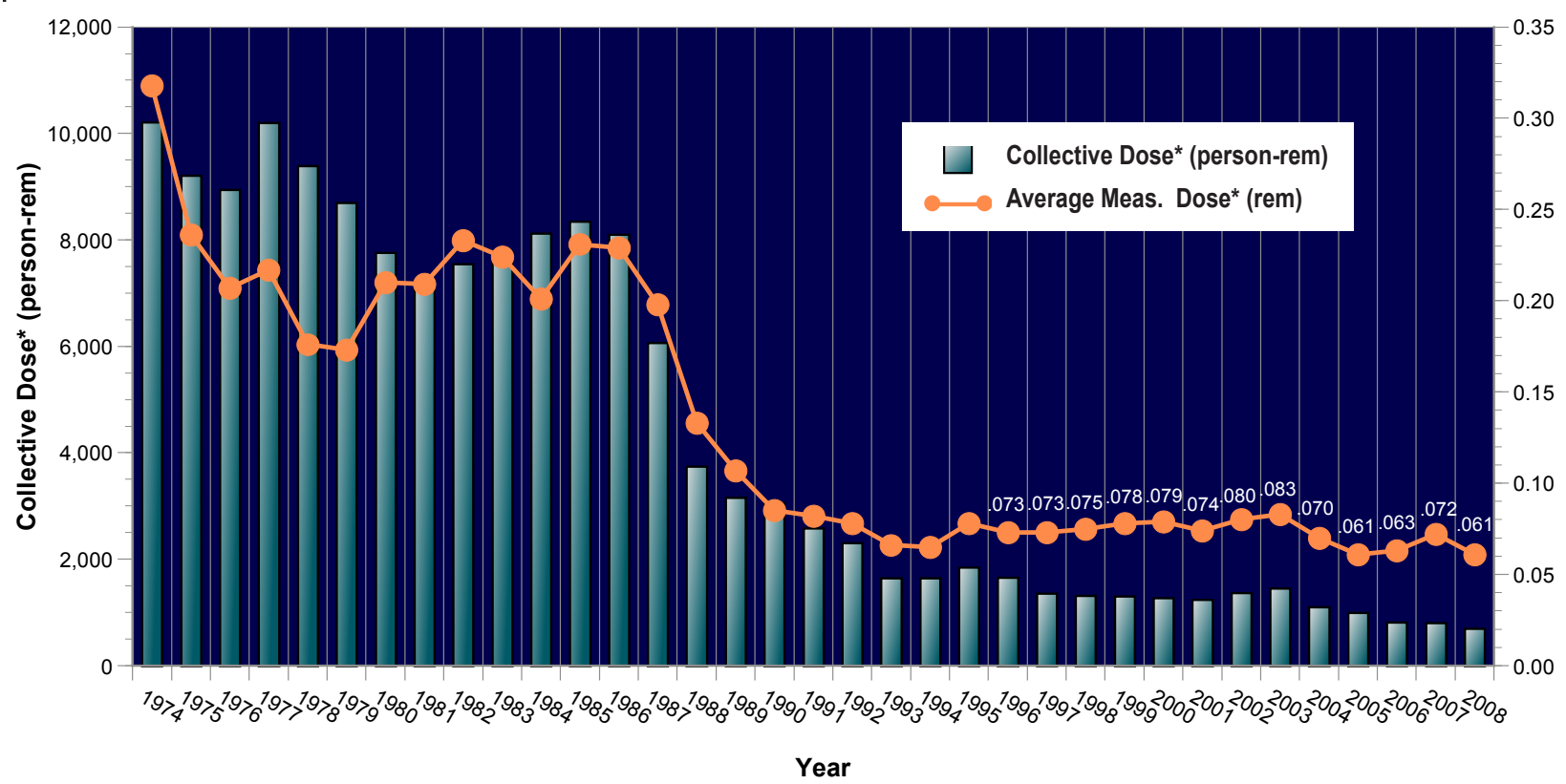

Exhibit 3-20:

Number of Workers with Measurable Dose and Average Measurable Dose, 1974-2008.

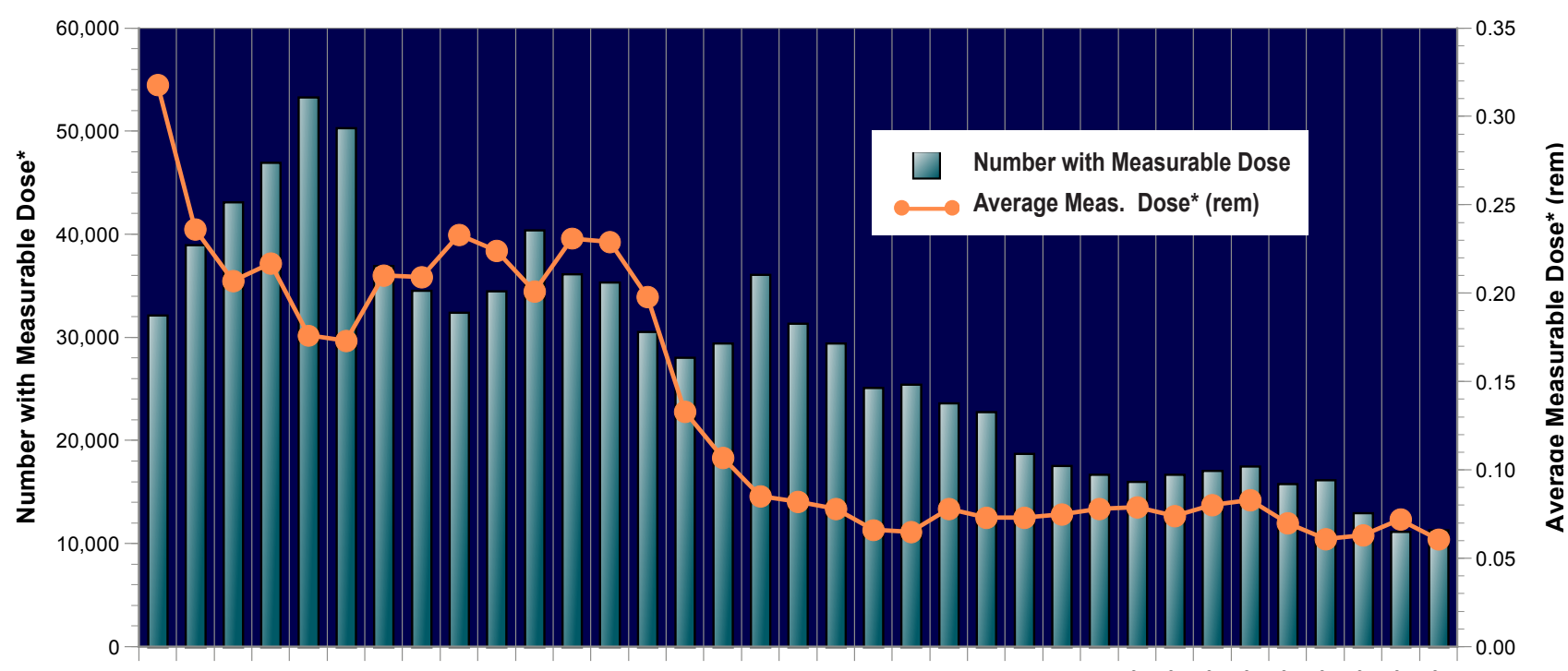

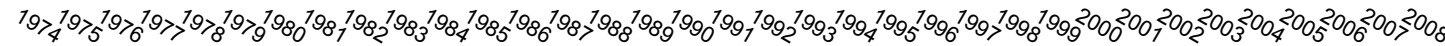

Year

* 1974-1989 collective dose = DDE

1990-1992 collective dose $=$ DDE + AEDE

1946-1974 Atomic Energy Commission (AEC)

1974-1977 Energy Research and Development Administration

1993-2008 collective dose $=$ DDE + CEDE

1977-Present Department of Energy (DOE) 
Exhibit 3-21:

Comparison of Occupational Exposure for DOE and NRC, 2004-2008.

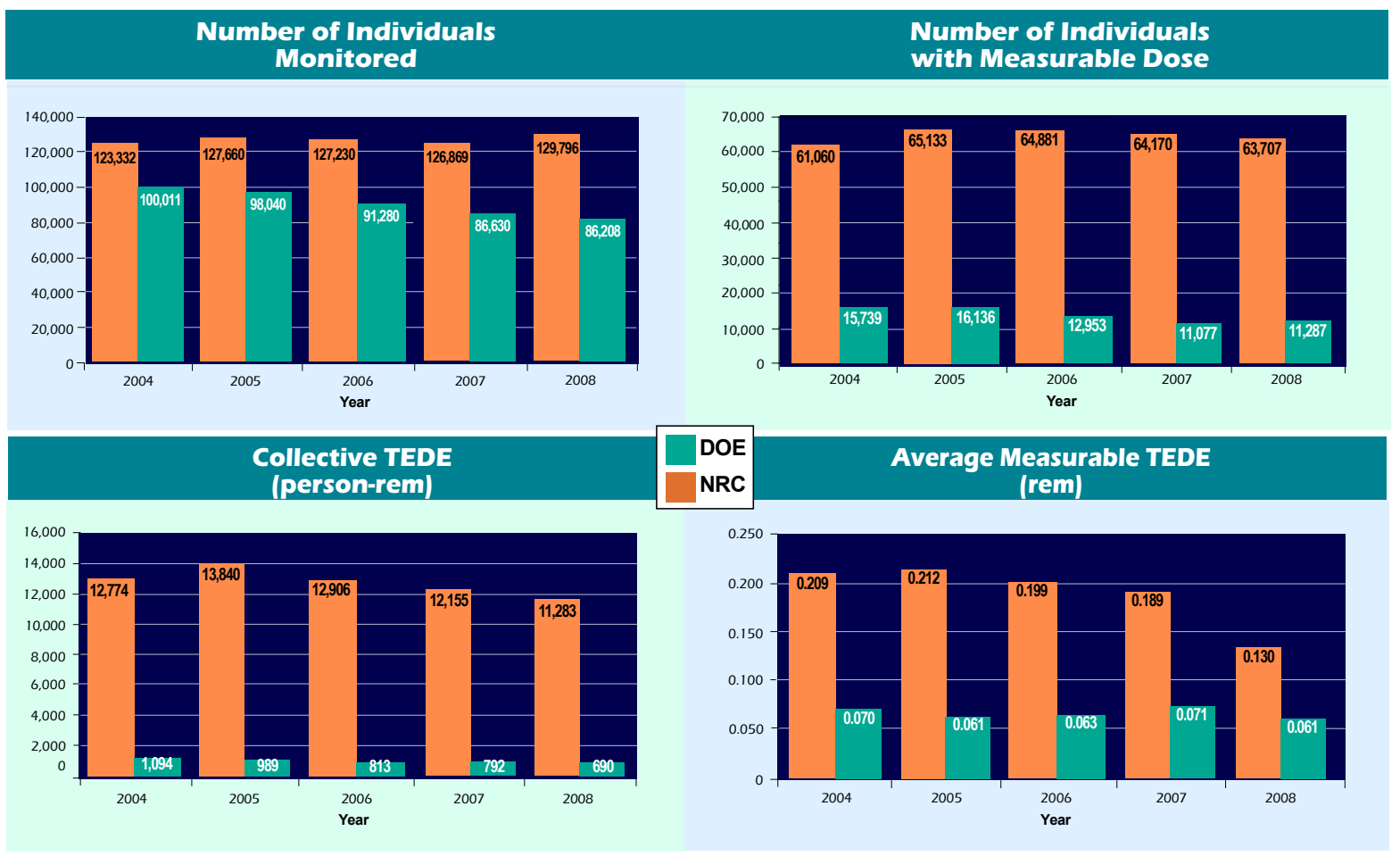

\subsection{Comparison of DOE Dose to Other Activities}

\subsubsection{Comparison with Activities Regulated by the Nuclear Regulatory Commission}

In the DOE Occupational Radiation Exposure Report 1992-1994, DOE occupational radiation exposure was shown in relation to other industrial and governmental endeavors in order to gain an understanding of the relative scale of the radiation exposure at DOE operations to other activities. The 2008 report includes the DOE occupational exposure in relation to activities regulated by the U.S. Nuclear Regulatory Commission (NRC). It should be noted that the purpose of this information is simply to put the DOE radiation exposure in context with other endeavors that involve radiation exposure. A comparison is not appropriate due to the differences in the missions of the DOE and NRC. While the mission of the DOE is broad in scope and includes activities from energy research to national defense, $\mathrm{NRC}$ licensed activities are dominated by radiation exposure received at commercial nuclear power plants. Reactor operations account for approximately $95 \%$ of the collective dose, while industrial radiographers, manufacturers, and distributors of radiopharmaceuticals, independent spent fuel storage installations (ISFSI), and fuel cycle licensees comprise the remainder.

The DOE and NRC occupational exposure data shown in Exhibit 3-21 cover the past 5 years (2004 to 2008).While the number of workers monitored at NRC and DOE are relatively comparable over the past 5 years, the number of individuals with a measurable dose at DOE was $23 \%$ of the NRC total for this time period. The percentages of the collective dose and average measurable dose were $8 \%$ and $34 \%$, respectively. 


\section{ALARA Activities at DOEll}

In past years, the published annual report has included descriptions of ALARA activities at DOE for the purposes of sharing strategies and techniques that have shown promise in the reduction of radiation exposure.

These ALARA activity descriptions are now provided on the HSS web site to facilitate the dissemination among DOE radiation protection managers and others interested in these project descriptions. Readers should be aware that the project descriptions are voluntarily submitted from the sites and are not independently verified or endorsed by DOE. Program and site offices and contractors who are interested in benchmarks of success and continuous improvement in the context of integrated safety management and quality are encouraged to provide input.

\subsection{Submitting ALARA Project Descriptions for Future Annual Reports}

Individual project descriptions may be submitted to the DOE Office of Corporate Safety Analysis through the REMS web site. The submittals should describe the process in sufficient detail to provide a basic understanding of the project, the radiological concerns, and the activities initiated to reduce dose. The web site provides a form to collect the following information about the project:

\footnotetext{
Mission statement

- Project description

- Radiological concerns

- Total collective dose for the project

$\checkmark$ Dose rate to exposed workers before and after exposure controls were implemented

- Information on how the process implemented ALARA techniques in an innovative or unique manner

Estimated dose avoided

- Project staff involved

- Approximate cost of the ALARA effort

- Impact on work processes, in person-hours if possible (may be negative or positive)

- Figures and/or photos of the project or equipment (electronic images if available)

- Point of contact for follow-up by interested professionals
}

The REMS web page for submitting ALARA project descriptions can be accessed on the Internet at

http://www.hss.energy.gov/CSA/analysis/rems/ rems/ALARA.cfm

\subsection{Operating Experience Program}

DOE has a mature operating experience program, which has been enhanced from the lessons-learned program that was initially developed in 1994.

The current DOE operating experience program is described in DOE Order 210.2, DOE Corporate Operating Experience Program [9]. The objective is to institute a Department of Energy (DOE) wide program for the management of operating experience to prevent adverse operating incidents and to expand the sharing of good work practices among DOE sites. The purpose is to provide a systematic review, identification, collection, screening, evaluation, and dissemination of operating experience from U.S. and foreign government agencies and industry, professional societies, trade associations, national academies, universities, and DOE and its contractors. The Headquarters corporate responsibility for identifying, analyzing, and sharing operating experience information, combined with the operating experience/lessons learned provided by DOE field sites, optimizes the knowledge gained and shared with others through various products, including a corporate database.

DOE posts operating experience information and links to other operating experience resources on the Internet. DOE uses the Internet to openly disseminate such information so that not only DOE but also other external entities will have a source of information to improve the health and safety aspects of operations within their facilities, including reducing the number of accidents and injuries. 
The specific operating experience web site address may be subject to change. Information services can be accessed through the HSS web site as follows:

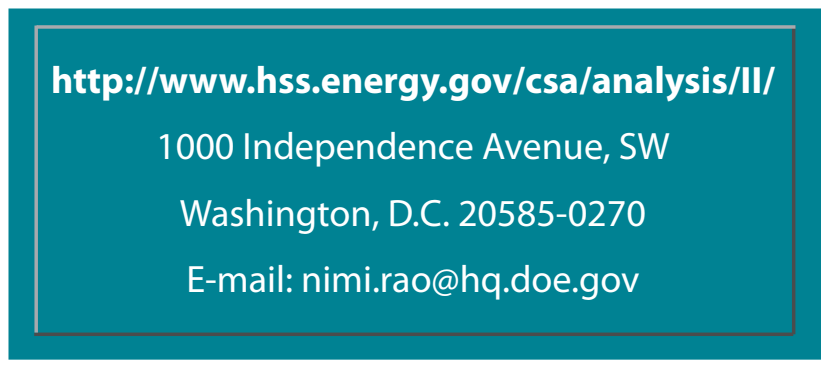




\section{Conclusions}

The occupational radiation exposure records show that in 2008, with the exception of only one individual, DOE facilities continued to comply with DOE dose limits and ACLs and worked to minimize exposure to individuals. Only $14 \%$ of the monitored workers received a measurable dose and the average measurable dose was less than $2 \%$ of the DOE limit. Although the number of individuals with measurable dose increased, the collective dose decreased. See Exhibit 5-1 for summary data.

Over the past 10 years, the collective dose and the size of the monitored workforce have remained at fairly stable levels. For the past 5 years, there has been a decrease in collective dose and the number of individuals with measurable dose.
The collective dose at DOE facilities has experienced a dramatic (90\%) decrease since 1986. This decrease coincides with the end of the Cold War era, which shifted the DOE mission from weapons production to stabilization, waste management, and environmental remediation activities along with the consolidation and remediation of facilities across the complex to meet the new mission. Also during this time period, regulations have improved with an increased focus on ALARA practices and risk reduction.

\section{Exhibit 5-1:}

2008 Radiation Exposure Summary.

There were no exposures in excess of the DOE 5 rems ( $50 \mathrm{mSv})$ annual TEDE limit, but there was one individual at LANL who received an organ dose in excess of the 50 rems (500 $\mathrm{mSv})$ limit as a result of an intake of plutonium from a puncture wound during glove-box work.

- There was one exposure in excess of the DOE ACL of 2 rems (20 mSv) TEDE. This same individual exceeded the 50 rems $(500 \mathrm{mSv}$ ) organ dose limit from an intake of plutonium.

The collective TEDE decreased 13\% from 798 person-rems (7.98 person-Sv) in 2007 to 690 person-rems (6.90 person-Sv) in 2008.

- Sites contributing significantly to collective dose were (in descending order of collective dose) Savannah River, Idaho, Oak Ridge, Los Alamos and Hanford. These sites accounted for $79 \%$ of the collective dose at DOE in 2008.

$\checkmark$ Decreases in collective dose at three of the highest dose sites were attributed to a reduction in dose rates and work activities at Hanford, a safety-driven pause in operations at LANL, and a reduction in the number of samples processed and source term at Idaho.

- The collective internal dose (CEDE) decreased by $11 \%$ between 2007 and 2008 due to a reduction in the number of internal doses for 2008 and an upward adjustment to the 2007 internal doses at Y-12 NSC.

$\checkmark$ Ninety-three percent of the collective CEDE at DOE was due to U-234, and over 99\% of the CEDE at DOE from $\mathrm{U}-234$ was accrued at Y-12 NSC.

The collective dose for transient workers decreased by 3\% from 22.1 person-rems ( $221 \mathrm{mSv}$ ) in 2007 to 21.4 person-rems $(214 \mathrm{mSv})$ in 2008.

- The total number of bioassay measurements performed decreased by less than $1 \%$ from 72,861 in 2007 to 72,346 in 2008. 
This page intentionally left blank. 


\section{Glossarys Sary}

administrative control level (ACL)

A dose level that is established below the DOE dose limit in order to administratively control exposures. ACLs are multitiered, with increasing levels of authority required to approve a higher level of exposure.

\section{ALARA}

Acronym for "as low as reasonably achievable," which is the approach to radiation protection to manage and control exposures (both individual and collective) to the workforce and the general public to as low as is reasonable, taking into account social, technical, economic, practical, and public policy considerations. ALARA is not a dose limit but a process with the objective of attaining doses as far below the applicable limits as is reasonably achievable.

\section{average measurable dose}

Dose obtained by dividing the collective dose by the number of individuals who received a measurable dose.This is the average most commonly used in this and other reports when examining trends and comparing doses received by workers, because it reflects the exclusion of those individuals receiving a less than measurable dose. Average measurable dose is calculated for TEDE, DDE, neutron dose, extremity dose, and other types of dose.

\section{collective dose}

The sum of the total annual effective dose equivalent or total effective dose equivalent values for all individuals in a specified population. Collective dose is expressed in units of person-rem.

\section{committed dose equivalent $(\mathrm{CDE})\left(\mathrm{H}_{\mathrm{T}}, \mathbf{5 0}\right)$}

The dose equivalent calculated to be received by a tissue or organ over a 50-year period after the intake of a radionuclide into the body. It does not include contributions from radiation sources external to the body. CDE is expressed in units of rem.

\section{committed effective dose equivalent $(\mathrm{CEDE})\left(\mathrm{H}_{\mathrm{E}}, \mathbf{5 0}\right)$}

The sum of the committed dose equivalents to various tissues in the body $\left(\mathrm{H}_{\mathrm{T}}, 50\right)$, each multiplied by the appropriate weighting factor $\left(\mathrm{w}_{\mathrm{T}}\right)$ (i.e., $\left.\mathrm{H}_{\mathrm{E}}, 50=\mathrm{w}_{\mathrm{T}} \mathrm{H}_{\mathrm{T}}, 50\right)$. CEDE is expressed in units of rem.

\section{CR}

See SR.

\section{deep dose equivalent (DDE)}

The dose equivalent derived from external radiation at a depth of $1 \mathrm{~cm}$ in tissue.

\section{DOE site}

A geographic location operated under the authority of the U.S. Department of Energy (DOE).

\section{exposure}

As used in this report, exposure refers to individuals subjected to, or in the presence of, radioactive materials that may or may not result in occupational radiation dose.

\section{lens (of the eye) dose equivalent (LDE)}

The radiation dose for the lens of the eye is taken as the external equivalent at a tissue depth of $0.3 \mathrm{~cm}$.

\section{members of the public}

Individuals who are not occupationally exposed to radiation or radioactive material.This includes visitors and visiting dignitaries. 


\section{number of individuals with measurable dose}

The subset of all monitored individuals who receive a measurable dose (greater than the limit of detection for the monitoring system). Many personnel are monitored as a matter of prudence and may not receive a measurable dose. For this reason, the number of individuals with measurable dose is presented in this report as a more accurate indicator of the exposed workforce. The number of individuals represents the number of dose records reported. Some individuals may be counted more than once if multiple dose records are reported for the individual during the year.

\section{occupational dose}

An individual's ionizing radiation dose (external and internal) as a result of that individual's work assignment. Occupational dose does not include doses received as a medical patient or doses resulting from background radiation or participation as a subject in medical research programs.

\section{shallow dose equivalent (SDE)}

The dose equivalent deriving from external radiation at a depth of $0.007 \mathrm{~cm}$ in tissue.

\section{SR (formerly CR)}

SR is defined by United Nations Scientific Committee on the Effects of Atomic Radiation (UNSCEAR) as the ratio of the annual collective dose delivered at individual doses exceeding a specified dose value to the collective dose. UNSCEAR uses a subscript to denote the dose value (in $\mathrm{mSv}$ ) used in the calculation of the ratio.Therefore, $\mathrm{SR}_{15}$ would be the ratio of the annual collective dose delivered at individual doses exceeding $1.5 \mathrm{rems}(15 \mathrm{mSv})$ to the total annual collective dose.

\section{total effective dose (TED)}

The sum of the effective dose (for external exposures) and the committed effective dose.

\section{total effective dose equivalent (TEDE)}

The sum of the effective dose equivalent for external exposures and the committed effective dose equivalent (CEDE) for internal exposures. DDE to the whole body is typically used as effective dose equivalent for external exposures. The internal dose component of TEDE changed from the annual effective dose equivalent (AEDE) to the CEDE in 1993.

\section{total number of records for monitored individuals}

All individuals who are monitored and reported to the DOE Headquarters database system. This includes DOE employees, contractors, subcontractors, and members of the public monitored during a visit to a DOE site. The number of individuals represents the number of dose records reported. Some individuals may be counted more than once if multiple dose records are reported for the individual during the year.

\section{transient individual}

An individual who is monitored at more than one DOE site during the calendar year.

\section{urinalysis}

The technique of determining the radiation dose received by an individual from an intake by the measurement of the amount of radioactive material in the urine excreted from the body. 
1. $\quad$ EPA (U.S. Environmental Protection Agency), 1987."Radiation Protection Guidance to Federal Agencies for Occupational Exposure," Federal Register 52, No. 17,2822; with corrections published in the Federal Registers of Friday, January 30, and Wednesday, February 4, 1987.

2. ICRP (International Commission on Radiological Protection), 1977."Recommendations of the International Commission on Radiological Protection," ICRP Publication 26, Annals of the ICRP, Vol. 1, No. 3 (Pergamon Press, New York).

3. NCRP (National Council on Radiation Protection and Measurements), 1987."Recommendations on Limits for Exposure to Ionizing Radiation," NCRP 91; superceded by NCRP Report No. 116.

4. 10 CFR 835, 1998, "Occupational Radiation Protection." Amended June 8, 2007. Rule; DOE Federal Register, November 4, 1998. Amended June 8,2007.

5. DOE Order 231.1A, 2003,"Environment, Safety and Health Reporting,"August 19,2003.

6. DOE Manual 231.1-1A,2004,"Environment,Safety and Health Reporting Manual," March 19, 2004.

7. Computerized Accident and Incident Reporting System (CAIRS),"DOE and Contractor Injury and Illness Data by Year by Quarter" report. Online at http://www.hss.energy.gov.

8. United Nations, 2000,Sources and Effects of Ionizing Radiation, United Nations Scientific Committee on the Effects of Atomic Radiation (UNSCEAR) 2000 Report to the General Assembly, with Scientific Annexes, Volume I, General Assembly of Official Records, United Nations, New York, 2000.

9. DOE Order 210.2,“DOE Corporate Operating Experience Program,” June 12,2006. 
This page intentionally left blank. 


\section{DOE Occupational Radiation Exposure Report}

\section{User Survey}

DOE, striving to meet the needs of its stakeholders, is looking for suggestions on ways to improve the $D O E$ 2008 Occupational Radiation Exposure Report. Your feedback is important. Constructive feedback will ensure the report can continue to meet user needs. Please fill out the attached survey form and return it to

Ms. Nirmala Rao

DOE HS-30

19901 Germantown Road

Germantown, MD 20874

nimi.rao@hq.doe.gov

Fax: (301) 903-1257
Questions concerning this survey should be directed to Ms. Rao at (301) 903-2297.

1. Identification:

Name:

Title:.

Mailing Address:

2. Distribution:

2.1 Do you wish to remain on the distribution for the report? yes no

2.2 Do you wish to be added to the distribution? yes no

(continued on back) 


\section{Please circle one.}

Please rate the usefulness of this report overall: $\quad$\begin{tabular}{ccccccc} 
Not Useful & \multicolumn{3}{l}{ Very Useful }
\end{tabular}

Please rate the usefulness of the analysis presented in the following sections:

$\begin{array}{llllll}\text { Executive Summary } & 1 & 2 & 3 & 4 & 5 \\ \text { Analysis of Aggregate Data } & 1 & 2 & 3 & 4 & 5 \\ \quad \text { Collective Dose } & 1 & 2 & 3 & 4 & 5 \\ \quad \text { Average Measurable Dose } & 1 & 2 & 3 & 4 & 5 \\ \quad \text { Dose Distribution } & 1 & 2 & 3 & 4 & 5 \\ \text { Analysis of Individual Dose Data } & 1 & 2 & 3 & 4 & 5 \\ \quad \text { Doses above 2 rems ACL } & 1 & 2 & 3 & 4 & 5 \\ \quad \text { Doses in Excess of 5 rems } & 1 & 2 & 3 & 4 & 5 \\ \quad \text { Internal Depositions of Radioactive Material } & 1 & 2 & 3 & 4 & 5 \\ \text { Analysis of Site Data } & 1 & 2 & 3 & 4 & 5 \\ \quad \text { Collective Dose by Site } & 1 & 2 & 3 & 4 & 5 \\ \quad \text { Description of Activities Related to Dose } & 1 & 2 & 3 & 4 & 5 \\ \text { Historical Data } & 1 & 2 & 3 & 4 & 5 \\ \text { ALARA Activities at DOE } & 1 & 2 & 3 & 4 & 5 \\ \text { Conclusions } & 1 & 2 & 3 & 4 & 5\end{array}$

Please rate the importance of the timeliness of the publication of this report as it relates to your professional need for the information on occupational radiation exposure at DOE:

$\begin{array}{ccccc}\text { Not important } & & & \text { Critical } \\ 1 & 2 & 3 & 4 & 5\end{array}$

Please provide any additional input or comments on the report. 

Prepared for the Office of Health, Safety and Security by Oak Ridge Associated Universities

P.O. Box 117 • Oak Ridge, TN 37831-0117 